\title{
Ocular toxoplasmosis: a review of the current diagnostic and therapeutic approaches
}

\author{
Dimitrios Kalogeropoulos (1D) Hercules Sakkas • Bashar Mohammed • \\ Georgios Vartholomatos • Konstantinos Malamos • Sreekanth Sreekantam • \\ Panagiotis Kanavaros $\cdot$ Chris Kalogeropoulos
}

Received: 9 November 2020/ Accepted: 30 July 2021 / Published online: 9 August 2021

(C) The Author(s), under exclusive licence to Springer Nature B.V. 2021, corrected publication 2021

\begin{abstract}
Purpose This review aims to summarize the current knowledge concerning the clinical features, diagnostic work-up and therapeutic approach of ocular toxoplasmosis focusing mainly on the postnatally acquired form of the disease.

Methods A meticulous literature search was performed in the PubMed database. A supplementary search was made in Google Scholar to complete the collected items.
\end{abstract}

D. Kalogeropoulos $(\bowtie) \cdot$ K. Malamos ·

C. Kalogeropoulos

Department of Ophthalmology, Faculty of Medicine,

School of Health Sciences, University of Ioannina,

Stavros Niarchos Ave, 45500 Ioannina, Greece

e-mail: dkalog1990@gmail.com

\section{H. Sakkas}

Microbiology Department, Faculty of Medicine, School of Health Sciences, University of Ioannina, Ioannina, Greece

B. Mohammed $\cdot$ S. Sreekantam

Birmingham and Midland Eye Centre, Birmingham, UK

G. Vartholomatos

Hematology Laboratory, Unit of Molecular Biology,

University Hospital of Ioannina, Ioannina, Greece

P. Kanavaros

Department of Anatomy-Histology-Embryology, Faculty of Medicine, School of Health Sciences, University of Ioannina, Ioannina, Greece
Results Ocular toxoplasmosis is one of the most frequent infectious etiologies of posterior uveitis. It typically presents with retinochoroiditis. Setting an accurate diagnosis depends to a considerable degree on detecting characteristic clinical characteristics. In addition to the evaluation of clinical features, the diagnosis of toxoplasmosis relies at a large degree on serologic testing. The detection of the parasite DNA in the aqueous or vitreous humor can provide evidence for a definitive diagnosis. The current mainstay for the treatment, if necessary, is the use of oral antibiotic with systemic corticosteroids. Recent evidence suggests other therapeutic approaches, such as intravitreal antibiotics can be used.

Conclusion Recent developments in the diagnostic and therapeutic approach have contributed to preventing or limiting vision loss of patients suffering from ocular toxoplasmosis. Further studies are required to provide a better understanding of epidemiology, pathogenesis, diagnosis, and treatment with a significant impact on the management of this challenging clinical entity.

Keywords Toxoplasma gondii - Ocular toxoplasmosis · Posterior uveitis · Retinochoroiditis 


\section{Introduction}

Ocular toxoplasmosis is caused by the obligate intracellular protozoan parasite Toxoplasma gondii (T. gondii) that can affect all warm-blooded vertebrates including humans [1]. T. gondii is one of the leading causes of infectious uveitis worldwide [2, 3]. After the infection, the majority of individuals present no symptoms at all, but it has been found that conditions, such as immunosuppression or congenital disease, may lead to severe disease. Ocular toxoplasmosis typically presents as posterior uveitis with a unilateral chorioretinal lesion and vitritis [4]. In pregnancy, primary infection can lead to several severe complications, including fetal death, congenital malformations or, at later stages of gestation, milder infections of neuronal tissues (e.g., brain or retina). Even though ocular toxoplasmosis in adults was perceived as a recurrence of congenital infection, recent evidence suggests that most cases with ocular involvement are most probably postnatal acquired infections [5]. Nevertheless, both routes of infection can lead to severe ocular involvement and may cause blindness. Prompt detection of the characteristic clinical features can be helped by positive serology for setting an accurate diagnosis; however, atypical manifestations can lead to diagnostic difficulties and eventually to misdiagnosis (e.g., in immunocompromised patients) and inappropriate treatment. This review aims to summarize the current knowledge about the clinical features, diagnostic work-up and therapeutic approach of ocular toxoplasmosis focusing mainly on the postnatally acquired form of the disease.

\section{Methodology}

A meticulous literature search was performed in the PubMed database. A supplementary search was made in Google Scholar to complete the collected items. The following keywords have been used to conduct our research: Toxoplasma gondii; ocular toxoplasmosis; posterior uveitis; and retinochoroiditis. We reviewed papers from 1908 to 2021, focusing on studies published after 2000, and using mostly those after 2010. Only references in English language were included. Additionally, the patients' archive from our unit was the source of figures used in this manuscript to support the importance of clinical, imaging and laboratory findings in the diagnostic work-up.

\section{Life cycle of $T$. gondii}

T. gondii belongs to the phylum Apicomplexa and can attach to the host cell membrane through a polar apical complex [6]. The infectious stages of $T$. gondii include sporozoites (contained within oocysts), tachyzoites and bradyzoites (residing in tissue cysts). Oocysts derive from cat (and other Felidae) intestines, and sexual reproduction is required. The size of sporulated oocysts is $11 \times 13 \mu \mathrm{m}$; oocysts contain two sporocysts, and each sporocyst contains four sporozoites enclosed in a cellular wall. After being released with defecation into the environment, they start being infectious within 1-5 days by sporulation. Tachyzoites (the fast reproducing form) measure approximately $6 \times 2 \mu \mathrm{m}$ and are in crescentic form (i.e., they have the apical complex in one end). Tachyzoites can invade most types of host cell and replicate until the cell is full of parasites, causing disseminated systemic disease and active tissue infection in intermediate hosts. The lysis of the host cell leads to the release of tachyzoites which is followed by re-entry into a new host cell. Multifocal tissue necrosis may occur as a result of this cycle. In most cases, the host suppresses this infectious phase and Toxoplasma passes to the dormant form of bradyzoites, which is typical in chronic infections, whereas bradyzoites can be detected in tissue cysts. Interestingly, the cysts contain hundreds of bradyzoites and their size may reach up to $60 \mu \mathrm{m}$. However, in most cases, they do not cause host reaction and remain inactive [7].

Humans can acquire an infection by various routes, including oral uptake (i.e., consuming food and water (containing oocysts), eating raw or undercooked meat of pigs and sheep-which are the dominant sourcesharboring tissue cysts, eggs or milk (containing tachyzoites), organ transplantation, blood transfusion or vertical transmission $[8,9]$.

\section{Epidemiology}

T. gondii is a ubiquitous microorganism, found all over the world, but the rates of infection are higher in tropical environments due to the beneficial effect of humidity and warmer temperature on the maturation of oocysts in the soil. In the USA alone, approximately 
250,000 referrals/visits to eye specialists were recorded over a two-year interval due to ocular toxoplasmosis [10]. The possibility of acquiring an infection displays a geographical variation and is strongly associated with factors such as the climatic conditions, release and distribution of oocysts, the animal reservoir, consumption of meat and other personal habits. The prevalence of $T$. gondii cysts in farm animals and the consumption of their meat can affect the rate of human infections. Due to the industrialization in meat production, sterilized livestock food and protection from rodents and cats, the risk of infection and seroconversion has dropped significantly in the majority of countries that imposed stricter hygiene standards and reduced consumption of raw or undercooked meat $[11,12]$. Prevalence rates of anti- $T$. gondii antibodies in humans vary widely, from approximately $20 \%$ in North America to $60-80 \%$ in France and Brazil $[8,9]$. A substantial reduction in seroprevalence has been recorded in many European countries [10]. However, it has been speculated that this decline in $T$. gondii exposure may be reversed in the future due to the ameliorated animal-friendly meat production and improvement in animal welfare and outdoor containment. This could probably result in an increase in $T$. gondii in meat and, therefore, to an increased risk for toxoplasmosis infections [13]. In contrast with Western countries, areas with rapid population growth and urbanization seem to present a higher risk of foodborne infection [14, 15]. Moreover, a substantially increased risk of infection has been recorded in China, Indonesia and Russia $[15,16]$. The quality of water is another significant risk factor, as contaminated water constitutes a source of epidemics associated with eye involvement [17, 18]. The prediction of global climate change in the upcoming years should also be taken into account regarding its impact on the prevalence of $T$. gondii [19].

\section{Pathophysiology}

The unique immunological status of the main immuneprivileged areas of the body (brain, eye and placenta) may create a delicate equilibrium between parasite invasion and host resistance. After the primary infection of intestinal epithelial cells, $T$. gondii circulates through the host's bloodstream and passes via vascular barriers, forming local cysts [20, 21]. Free tachyzoites have recently been detected in human blood samples but it is still considered unlikely that these parasites can directly infect the ocular tissue. The dendritic cells and macrophages transport the parasite to the target tissues $[21,22]$. Invasion of the host cell is an active parasitedriven process, facilitated by several parasite-host surface ligands. These attachments activate calciumdependent protein kinases, regulating the parasite invasion [23]. During intracellular infection, the parasite protects itself from toxic host molecules, whereas the host cell remains passive with minor alterations of repressor of primer (ROP) and STAT3/6 (signal transducer and activator of transcription), with further effects on intracellular signaling pathways. Interestingly, the parasite releases immune modulators [such as repressor of primer (ROP) and granule (GRA) proteins] into the cytoplasm of the host cell and triggers the production of IFN- $\gamma$ and IL-12 (pro-inflammatory cytokines), while it simultaneously suppresses an intense Th1 immune response [24-26]. Subsequently, there is a unique equilibrium in the immune response that enables the immunological regulation of the parasite, while it impedes immunopathological effects. Th17 cells are defined by the secretion IL-17 mediated by the secretion of IL-23 from dendritic cells, suggesting that the existence of both pro-inflammatory and protective effects [24-26]. Furthermore, in active ocular toxoplasmosis, the finding that overexpression of IL-17A was caused by resident retinal cells may have several direct implications in terms of pathogenetic mechanisms and therapeutic approaches [24]. On the other hand, IL-17 has substantial neuroprotective properties by maintaining homeostasis, inhibiting intracellular calcium and preventing cell apoptosis in active uveitis [27]. Although IL-17A is a recognized mediator of pro-inflammatory responses and autoimmune disorders, its role in infectious diseases remains unclear, as it sways between tissue destruction and anti-pathogenic activity. The cytokine milieu and the disease's stage are associated with several infectious and inflammatory events. Parasite- and host-related parameters are critical in determining whether a toxoplasmic infection will lead to ocular involvement [24-26].

Factors associated with the severity of the clinical manifestations

Hogan had suggested that the "virulence" of the parasite causing an infection determines the severity of the disease caused in humans [28]. It has been found 
that there may be indeed a crucial biological background explaining the variations among isolates that affect the course of human disease. Apart from the specific isolate and the type of animal host, a wide spectrum of factors determines the disease severity. There is evidence of host (e.g., patient's age and immune status) and parasite-related factors that affect the poignancy of the disease, as well as environmental-related factors that influence the interactions between the host and the parasite [29].

Results deriving from genetic analyses indicate that most parasites detected in Europe, North America or other areas, belong into one out of three intimately related genotypes, recognized as I, II and III [30]. These three types derive from two ancestral strains (A and E) [31]. Each genetic locus of this haploid microorganism has an allele derived from one of these two ancestral strains and each genotype is described by a different combination of these alleles. As only three allelic combinations have prevailed over a wide spectrum of geographic areas and hosts shows that there is a survival advantage of these clonal lineages. This feature is partially attributed to the parasite's ability to infect intermediate hosts directly through the ingestion of tissue cysts. The sexual reproduction cycle can be circumvented, as the progeny of asexual reproduction are infectious to other intermediate hosts. Although there can be a mixing of cycles and the fact that ingestion of oocysts also leads to infection, unique recombinants from sexual reproduction are detected less often in comparison with members of the three dominant genotypes [32]. In particular, Type II parasites cause infection via the oral route, indicating why they are the most frequently detected isolates [32]. According to results from genetic mapping studies, there are loci similar to type I parasites that play a significant role in virulence [33]. However, virulence varies as it depends on the interaction of several combinations of particular alleles at multiple loci. Furthermore, it may be associated with variations of the immune responses in each host and with differences among types in their ability to go through physiologic barriers [34]. Such a correlation between the parasite time and the human disease has been speculated but the source of infection cannot usually be verified and parasites are rarely isolated from the host [35]. Type II parasites are mostly responsible most infections in immunocompromised individuals in North America and
Europe, but significant rates of the other two types have also been recorded [30]. Furthermore, type II parasites are associated with the majority of congenital infections in North America and France [30], whereas congenital infections in Spain presented a stronger correlation with type I parasites [36]. However, there is a disproportionately high percentage of infections with type II parasites in livestock of the same geographic areas [30]. It has been suggested that there may be a relationship between the severity of ocular involvement in humans and the genotypes of $T$. gondii [37]. More specifically, in immunocompetent individuals, the type of the parasite appears to have a substantial effect on the ophthalmological manifestations. Infection by type I parasite can lead to severe disease, but type II (or even type III) parasite may result in mild or no ocular disease. On the contrary, host parameters are more crucial in immunocompromised or immunosuppressed patients, as severe disease is potentially caused by any parasite type [37]. Apart from the course of the disease, the type of the parasite may influence the treatment efficacy [29]. Overall, the ability to discriminate with certainty between type II and non-type II parasites alone will improve our understanding of epidemics and contribute to treatment decision-making.

Various situational factors may affect the frequency, presentation and course of the disease. Results from experimental studies in mice have shown that the severity of the disease may fluctuate not only due to the strain of parasite and type of mouse, but also by the parasite's stage, route of infection, and amount of inoculums [38].

The geographic area of origin, rather than race, affects the risk of disease. In London, the prevalence of toxoplasmic retinochoroiditis is higher in Africans born in West Africa than in the rest of the population, even those who were born in East Africa, West Indies or Britain [39].

Additionally, in some age groups, the prevalence of T. gondii infection in Mexican-Americans is higher in comparison with the general population in the USA [31].

Probably, the prevalence of $T$. gondii infection in some geographic areas and in some racial/ethnic groups is associated with various cultural parameters that cause variations to the exposure (e.g., age of infection, stage and amount of parasitic inoculum) [29]. 

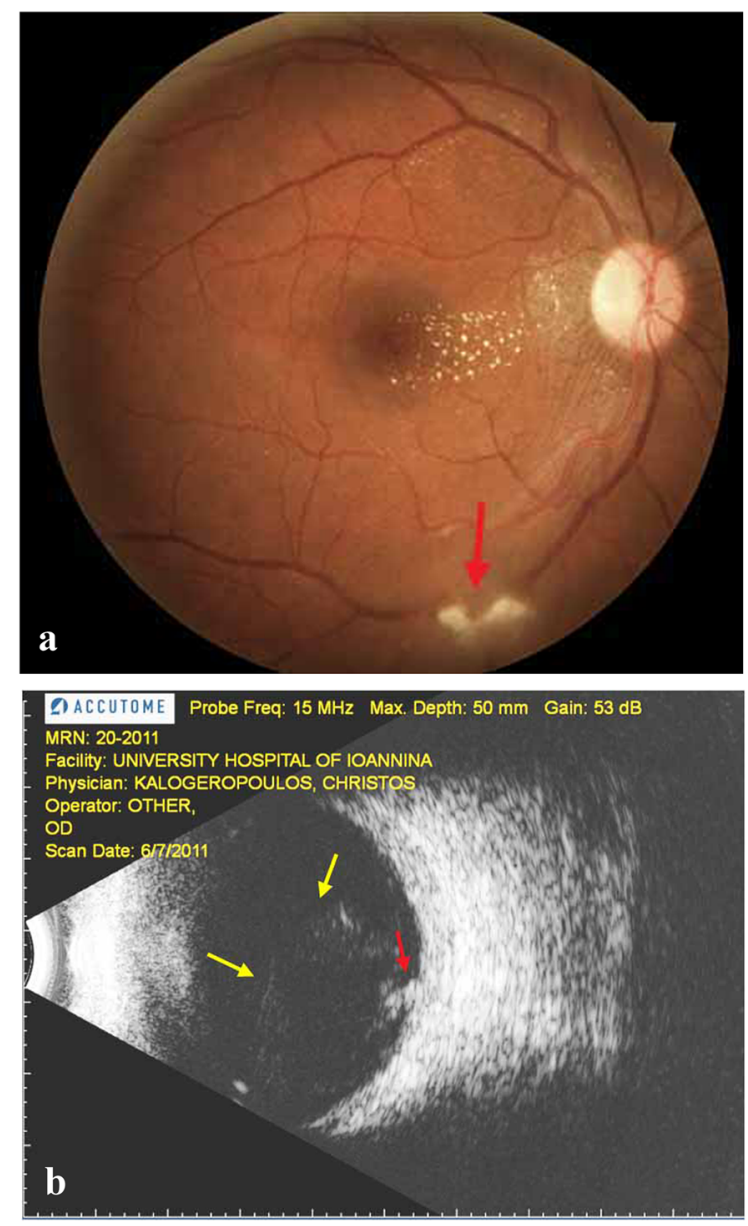

Fig. 1 a Active toxoplasmic retinitis (red arrow) with a slightly hazed overlying vitreous. Note the presence of a mild neuroretinitis. b B-Mode of the same patient showing focal vitritis (yellow arrows) near the active lesion (red arrow)

\section{Symptoms and sings}

Symptoms and clinical features of ocular toxoplasmosis are related to the anatomical localization of the pathological lesions [1]. Although adults and verbal children may complain of any visual disturbance, the perception of symptoms in preverbal children may delay the diagnosis of ocular involvement. Additionally, not all adults and older children can detect the symptoms if they do not derive from the posterior segment or present with a severe inflammatory response. A considerable visual deterioration may manifest due to macular involvement, whereas peripheral lesions may not have an obvious effect on vision [40]. Regarding the active lesions, the vitritis is mostly

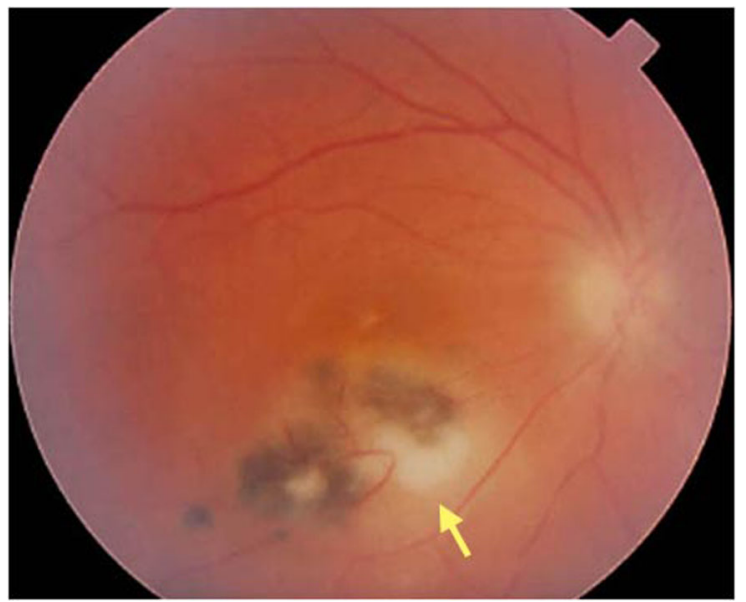

Fig. 2 A new active lesion of retinitis (yellow arrow) due to recurrence of toxoplasmic retinochoroiditis, adjacent to older lesions (scarred areas with pigmentation)

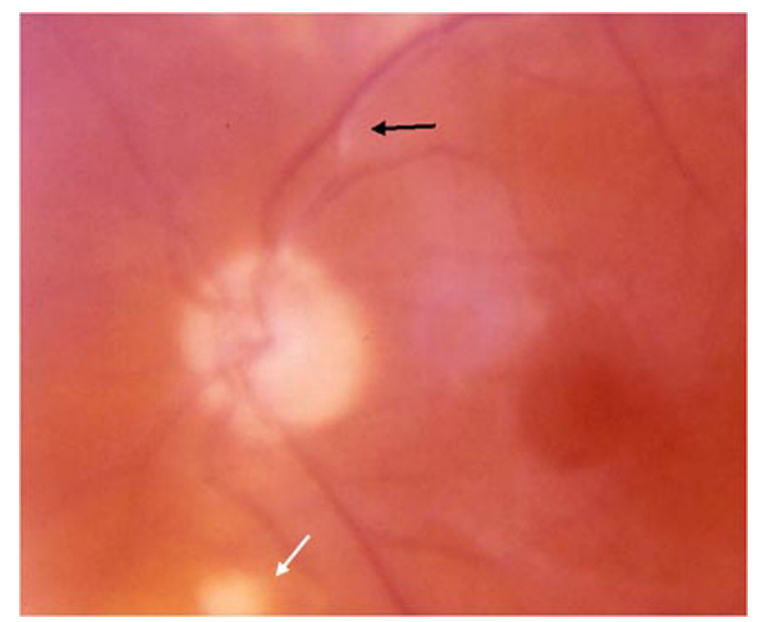

Fig. 3 Kyrieleis arteritis in toxoplasmic retinochoroiditis presenting as a segmental intravascular white plaque (black arrow). The active retinochoroidal lesion is indicated by the white arrow

the first factor causing visual symptoms. However, diminished visual acuity or even a scotoma may also contribute to the diagnostic approach. On the other hand, in an inactive lesion, there is a direct correlation to the location and the size of the chorioretinal scars. Vitreous opacities may persist even after the resolution of the inflammation, confusing patients with poor vision who may not be able to distinguish these opacities from signs of recurrent inflammatory activity. On the contrary, patients with normal visual acuity may detect more easily floaters of newer onset [1]. 
Clinical features

Typically, retinochoroiditis is the most prevalent feature of active intraocular inflammation in patients with ocular toxoplasmosis and, in most cases, is enough for setting a clinical diagnosis without further diagnostic investigations. Retinochoroiditis usually presents together with focal necrotizing granulomatous retinitis, reactive granulomatous choroiditis, vitritis and even inflammatory activity of the anterior segment. However, many cases may present with substantial clinical variations leading to diagnostic difficulties [41]. Reactivations can happen any time after the primary infection due to the rupture of intraretinal cysts, triggering a rapid localized immune reaction. It must be underlined that the absence of posterior segment scarring is not pathognomonic of recent toxoplasmic infection and cannot exclude the possibility of congenital toxoplasmosis [42]. Improved knowledge of the spectrum of clinical manifestations can contribute to the understanding of the pathogenetic mechanisms and approach of the disease [43].

\section{Anterior uveitis}

Anterior segment inflammation (granulomatous or non-granulomatous) varies from a quiet anterior chamber to intense anterior uveitis. Intense inflammation may obscure the underlying retinitis. Delayed diagnosis and prolonged inflammation may lead to severe iris synechiae. The retinochoroiditis near the ora serrata can also lead to intense anterior chamber inflammation [1].

\section{Vitritis}

Vitreous inflammation tends to be more prominent near the active lesions of retinochoroiditis (Fig. 1a, b). However, vitritis may be absent if the retinal inflammation does not extend to the inner limiting membrane. Severe vitritis can lead to the epiretinal membrane formation with subsequent vitreoretinal traction near the area of retinochoroiditis. Delays in commencing the appropriate treatment are related to more intense and persistent inflammation. The term "headlight in the fog" is used to describe the phenomenon of the bright white reflex seen through intense vitritis during indirect fundoscopy. [1].

\section{Retinochoroiditis}

Acute ocular toxoplasmosis manifests as a welldefined focus of retinal necrosis vitritis. Diffuse inflammation in the adjacent retinal and choroidal tissue may also be present. The involvement of the underlying choroid is termed "retinochoroiditis" and describes the clinical image. Active lesions are described as whitish foci, with obscure borders, frequently close to an atrophic or pigmented scar (Fig. 2). Vasculitis can be seen near or even remote from the lesion. Periphlebitis is more common compared to arteritis, while retinal hemorrhages may also be present. Vasculitis can expand to other distant retinal areas, especially in cases of severe inflammation [1]. A rare pattern of arteriolitis known as Kyrieleis arteritis can also be observed in some cases (Fig. 3). Kyrieleis arteritis presents as segmental intravascular white plaques that appear nodular and do not extend outside the vessel [44, 45]

In immunocompetent patients, the active lesions tend to heal automatically within the next 2-4 months leaving an atrophic area (resolving from the periphery to the center) that gradually leads to hyperpigmented scar due to the retinal pigment epithelium (RPE) disruption. Histopathological investigations are not usually available, but results from AIDS patients revealed $T$. gondii antigens in the areas of retinal necrosis [46]. Parasites were also detected by immunohistopathology, which were found to be endued by an inflammatory cell infiltrate in more than half of the investigated eyes from fetuses with congenital toxoplasmosis [47]. A murine model of congenital ocular toxoplasmosis highlighted the great variations from low-grade retinal infiltration to extensive necrotic destruction affecting all layers (including the outer retina, RPE and choroid) [48]. T. gondii cysts were not considered as the main focal point of inflammatory infiltrates. In some specimens, the presence of cysts has been confirmed in remote areas from scars, within the inner retinal layers of the uninfluenced retina with no evidence of inflammation. Macrophages had partially phagocytosed the photoreceptor outer segments, suggesting that tissue damage may be linked to autoimmune mechanisms. Apart from transient inflammatory reactions during a $T$. gondii infection, the existence of active retinal lesions is a prerequisite for the existence of intraocular inflammation. Partial lesions affecting the deeper 
retinal layers cause minor or no vitritis. A relationship between the size of retinochoroidal infiltrates and the severity of vitritis may be possible but this is yet to be defined [49]. Acute lesions are usually adjacent to old scars, indicating recurring episodes in satellite sites. On their first ophthalmological examination, more than $70 \%$ of patients are found to have both an active lesion and an older retinal scar (that has been healed), implying that peripheral retinitis can be missed in several cases [17]. However, it has not been yet fully clarified whether the initial events follow a less severe
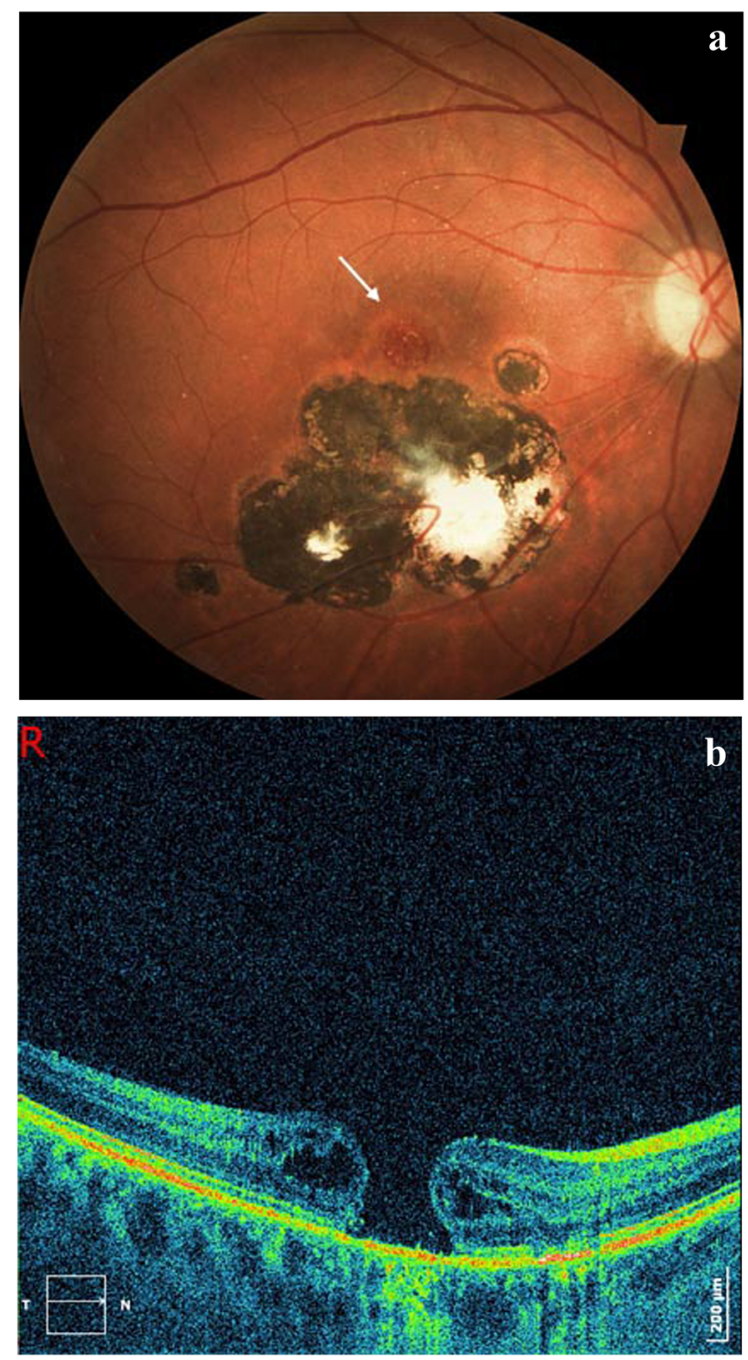

Fig. 4 Patient of Fig. 2, 8 years after the last recurrence of toxoplasmic retinochoroiditis. a Macular hole (white arrow) adjacent to severe old lesions. b Optical coherence tomography (OCT) scan with a characteristic imaging of a full-thickness macular hole course in comparison with the recurrences of ocular toxoplasmosis [49].

\section{Punctate outer retinal toxoplasmosis (PORT)}

PORT is defined by small, multifocal lesions located in the deep layers of the retina and RPE. It is considered that it derives from both parasite and host factors. As the inflammatory process is restricted to the outer retinal, vitreous inflammation is usually nonsignificant or even absent. After the acute phase, fine granular gray-white lesions will remain. Quite frequently, optic neuropathy may also occur secondarily, leading to significant visual loss [50]. It has been reported that the vast majority of patients with
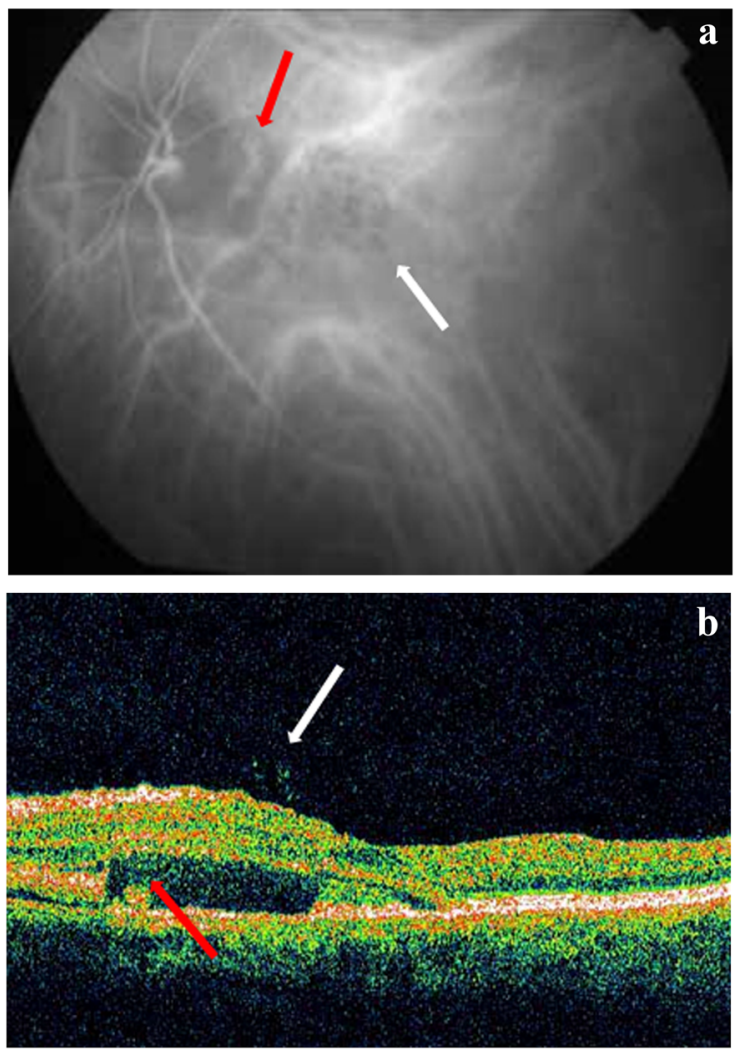

Fig. 5 a Indocyanine green angiography (ICGA) of a patient with punctate outer retinal toxoplasmosis (significantly elevated IgG titers). Note the hypofluorescent punctate lesions (white arrow) and the neovascular choroidal membrane (red arrow) as a complication of the inflammatory process. b Optical coherence tomography (OCT) of the same patient with vitreous hyperreflective spots or hyaloid bodies (white arrow) and subretinal exudative fluid (red arrow) due to the adjacent neovascular membrane 
punctate outer retinal toxoplasmosis were within their first twenty years of life [51]. This manifestation has been correlated with both congenitally and postnatally acquired infections. Bilateral involvement was observed in one-third of patients. Others presented with typical ocular toxoplasmosis findings in one eye and PORT in the fellow eye. The significance of multimodal imaging in PORT was delineated by Yannuzzi et al. who used optical coherence tomography (OCT), fundus autofluorescence (FAF), optical coherence tomography angiography (OCTA), and conventional dye-based angiography (FAG, ICGA) to investigate a cohort of patients with ocular toxoplasmosis. This study found that the contribution of multimodal imaging was substantial in differentiating this uncommon presentation of ocular toxoplasmosis from white dot syndromes or other etiologies of unilateral retinitis [52].

\section{Neuroretinitis}

A few cases of neuroretinitis defined by optic nerve edema and hard exudates presenting in a "star pattern" have been reported [53]. However, these features are mostly observed in neuroretinitis attributed to Bartonella-related infections. Papillomacular retinal detachment and splinter hemorrhages have also been described [54]. Optic neuritis together with necrosis and parasite infiltration has been reported as an early clinical feature in patients with HIV and cases with fulminant congenital ocular toxoplasmosis [55]. Optic nerve involvement can derive either from direct nerve involvement (pure papillitis), also including insult due to a juxtapapillary retinochoroiditis or secondary to a retinal lesion detected remotely from the optic nerve [56].

\section{Scleritis}

Regarding ocular tissues $T$. gondii is typically detected in the retina [57]. However, in parasites, they have been rarely found in the sclera of HIV-positive individuals with extensive retinal inflammation [58]. As for the choroidal involvement, the subjacent area of retinal inflammation may cause the spreading of the inflammation overlying the sclera and manifest as scleritis [58].
Complications

Anterior segment inflammation can lead to elevated intraocular pressure due to obstructions of the trabecular meshwork with cellular debris and inflammatory cells. Additionally, a raise of the intraocular pressure is also significantly associated with vitritis. In general older patient's age, retinal lesions larger than one disk area and active extra-macular lesions were correlated to intense intraocular inflammatory activity [59].

Involvement of the maculopappilary bundle, optic nerve, or fovea has been associated with impairment of the central vision [60]. Vascular complications, such as retinal vasculitis, proliferative vitreoretinopathy and tractional bands, can potentially cause vitreous hemorrhage and tractional retinal detachment. Immunocompromised patients with large necrotic areas have an elevated risk for retinal breaks and eventually retinal detachment. In general, secondary tractions can lead to retinal tears, macular edema and vitreomacular traction. Prolonged vitritis may be responsible for the development of epiretinal membranes that can be surgically removed after the active stage of inflammation with favorable outcomes [61]. In addition, cases with full-thickness macular holes (Fig. 4a, b) have been described as the result of epiretinal membrane, vitreomacular traction or a thin and fragile retina due to severe and/or recurrent inflammation [62]. Occlusion of vessels (both arteries and veins) is more possible to occur when a vessel passes through an active lesion [63].

Alterations affecting Bruch's membrane promote the formation of choroidal neovascular membranes (Fig. 5a, b). The implementation of intravitreal antiVEGF agents is beneficial in terms of functional and morphologic ameliorations [64], enhancing the theories about the role of pro-inflammatory cytokines and vascular growth factors [65].

Serous retinal detachment is another complication of retinochoroiditis. These cases are generally defined by moderate vitritis. In some cases, it may extend remotely from the site of retinochoroiditis and lead to substantial visual acuity deterioration when they approach the macula [1].

\section{Imaging}

Apart from the basic ophthalmological assessment, further examinations and imaging techniques 
Fig. 6 Retinal imaging in a patient with ocular toxoplasmosis. a Primary acute toxoplasmic retinitis without other lesions in the surrounding area. b In the arterial phase of

fluoroangiography (FA) a masking effect corresponds to the inflamed retina. $\mathbf{c}$ In the mid-venous FA phase vasculitis is indicated by a red arrow.

d Hyperfluorescence of the inflammatory lesion during the transit FA phase (leakage from the dilated vessels in the area of the lesion). Note that the optic disk is also involved
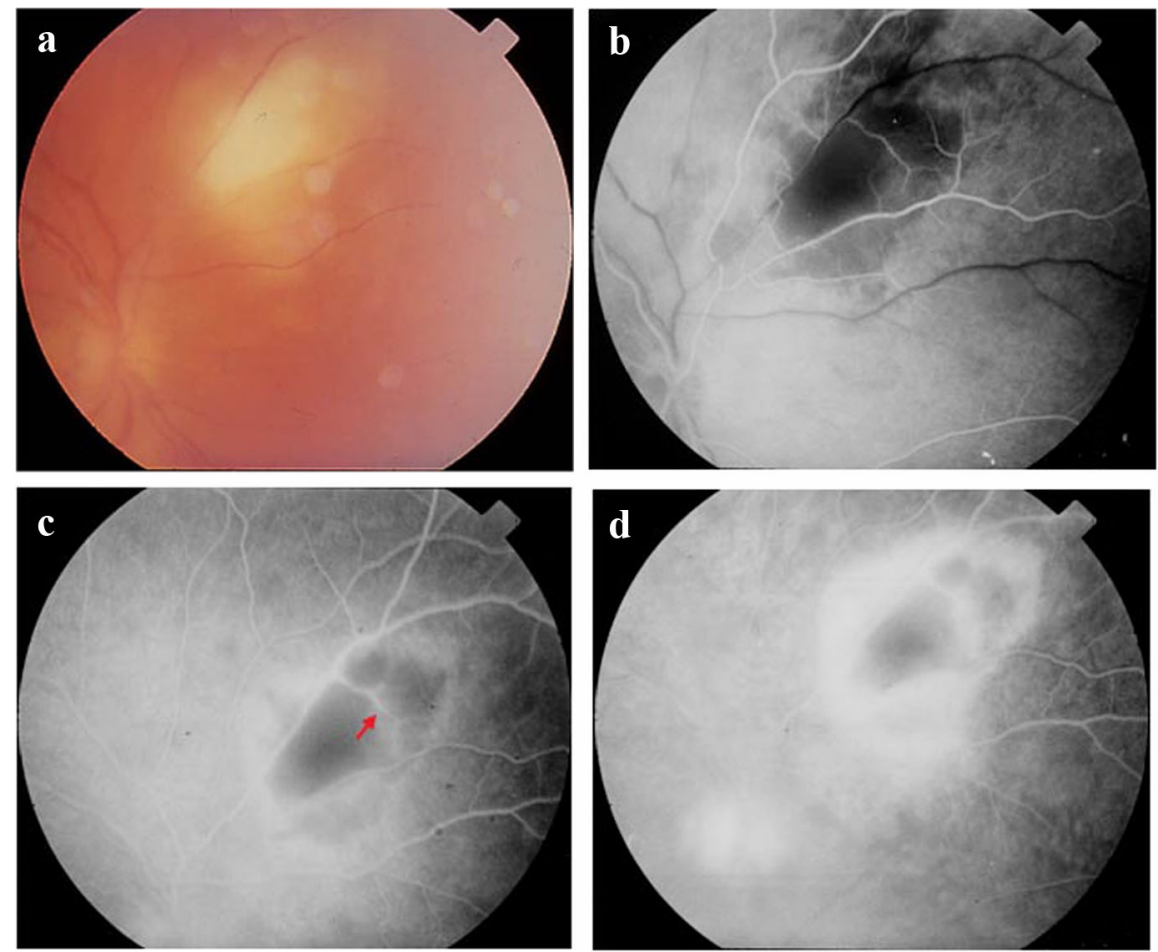

including fundus color photography (FCP), OCT, OCTA, ultrasound (US), confocal scanning laser ophthalmoscopy (CSLO), fluorescent angiography (FA), FAF, and ICGA may be required in order to record findings and evaluate lesions and various complications such as vascular occlusion, retinal neovascularization, macular edema, vitreous hemorrhage, subretinal neovascular and epiretinal membranes, or other ocular abnormalities. Appropriate imaging is substantial for the follow-up and the detailed illustration of toxoplasmic lesions, inflammatory activity and relevant complications. This is essential for the longitudinal assessment of lesions, particularly in cases of recurrences. Subsequently, imaging contributes to the consultation of patients offering significant information regarding the diagnostic and therapeutic approach [66].

\section{Fundus color photography (FCP)}

Color photography of the fundus, especially wide field, provided an essential tool for monitoring for non-central lesions. Comparison between photos to recognize early pigmentation of the lesions' edges indicates healing as mentioned before and may depict significant findings (e.g., hyperpigmented old scars) that can be missed at the clinical examination. It is also useful for recording the location, extent and progress of the lesions at the posterior segment [66].

Fluorescent angiography $(F A)$ and indocyanine green angiography (ICGA)

FA and ICGA constitute classic techniques that can be facilitated can be used for monitoring the evolution of the lesions but are not always necessary. Angiography can be extremely useful for defining various pathologies such as vascular occlusions, vasculitis shunts, macular edema and neovascular membranes [67]. FA can demonstrate signs useful to confirm the activity of each lesion. For instance, FA can contribute to detecting early, small active lesions that may be located in close proximity with an older scar. Typically, in active ocular disease, a masking lesional effect at the early phases is followed by a hyperfluorescence progressing from the periphery to the center of the lesion (Fig. 6a-d) [1]. Vasculitis nearby to the lesion is illustrated as a gradually increasing hyperfluorescence of the vessel walls. Pigmentary alterations are best highlighted with FA; they have a lasting 
masking effect, usually bounded by a line of hyperfluorescence. Papillitis is typically depicted as an early staining of the optic disk, defined by a persistent hyperfluorescence. In cases of severe inflammation, cystoid macular edema will also be revealed by FA, even distantly from the active lesion [1]. After the resolution of the inflammation, a chorioretinal scar can be observed. ICGA defines the extent of choroidal involvement and in some special cases the progress of lesions as well [67].

\section{Confocal scanning laser ophthalmoscopy (CSLO)}

The function of CSLO is based on an optically pumped solid-state laser that generates excitation at a specific wavelength [e.g., $488 \mathrm{~nm}$ for blue reflectancy for FAF and FA, $787 \mathrm{~nm}$ for ICGA, and $830 \mathrm{~nm}$ for infrared reflectance (IR)]. In contrast with other techniques, the higher emission of light provides the acquirement of images of better quality when it comes to media with opacities [68]. Red-free mode is useful for recognizing pathologies of the retinal surface, such as membranes, internal limiting membrane irregularities, retinal folds or cysts. IR delineates features such as (i.e., lens and vitreous opacities). IR is also helpful for assessing melanin contents of RPE and choroid [69]. In the acute stages, IR reveals a lesion with increased reflectivity at its center but reduced signal over the surrounding tissues. Finally, IR can contribute to describing vascular abnormalities (e.g., increased tortuosity and reflectivity over the vessel's walls).

\section{Fundus autofluorescence (FAF)}

FAF can be used for revealing RPE anomalies and can be recorded either by CSLO or by a modified digital system [70]. Extensive granulomatous inflammatory RPE infiltration and choroid resulting in significant subretinal fibrosis have been described in eyes with retinal toxoplasmosis. The signal may depend on the stage and level of inflammatory activity. In the acute stage, identifying the lesion may be difficult due vitreous opacities. However, a patch of decreased FAF signal combined with increased perilesional autofluorescence can be seen during the early settings of ocular toxoplasmosis. Thus, retinal atrophy and scarring and fibrosis (in advanced stages) create a predominantly low FAF signal. Satellite lesions present as smaller increased or decreased FAF patchy lesions and vary according to the time point of onset.

\section{Optical coherence tomography (OCT)}

OCT enables the imaging of the retinal, choroid, and vitreoretinal interface [71] and has developed as a valuable imaging technique in uveitis and particular ocular toxoplasmosis. It is vital in creating a more consistent opinion on abnormalities of the posterior segment such as characteristic hyperreflective spots in the vitreous (hyaloid bodies), retinal edema, vitreoretinal tractions, epiretinal membranes and neovascular membranes (Fig. 5b). Additionally, it can be used for recording the macular retinal thickness, measuring lesions and monitoring possible alterations as well as response to treatment. Differential diagnosis between older scars and new inflammatory foci can also be supported by OCT [66].

\section{Optical coherence tomography angiography (OCTA)}

Apart from OCT, OCTA can detect uncommon structural and vascular alterations of the posterior segment in active and post-treatment, providing critical information for clinical practice in patients with toxoplasmic retinochoroiditis. A relevant study [72] assessed 15 eyes of 15 patients with active toxoplasmic retinochoroiditis before and after treatment. The main findings included hyperreflective inner retinal layers with full-thickness disorganization of the retinal reflective layers at the area of the active retinochoroiditis. Moreover, all eyes presented a choroidal hyporeflective signal, whereas $80 \%$ of eyes had focal choroidal thickening under the site of retinitis. It appears that OCTA can illustrate vascular processes, especially in cases that the use of dye injection may be contraindicated [73, 74]. The evaluation of other abnormalities, such as choroidal neovascular membrane (CNVM) secondary to inactive toxoplasmosis, by OCTA has also been reported [75].

\section{Ultrasound (US)}

Opaque media (e.g., corneal opacification, lens or vitreous opacities) can cause important difficulties in examining the posterior segment and therefore in detecting inflammatory activity. Ultrasonography, in 
Table 1 Serological tests for Toxoplasma gondii infections

\begin{tabular}{|c|c|c|c|}
\hline Name of serological test & Advantages & Disadvantages & Special features \\
\hline $\begin{array}{l}\text { Sabin-Feldman dye test } \\
\text { (DT) }\end{array}$ & $\begin{array}{l}\text { Still considered the gold } \\
\text { standard test of toxoplasma } \\
\text { serology } \\
\text { Highly sensitive, specific, and } \\
\text { quantitative }\end{array}$ & $\begin{array}{l}\text { It can only be carried out in } \\
\text { reference centers due to the } \\
\text { requirement for live } \\
\text { tachyzoites, which are } \\
\text { amplified in mouse peritoneum } \\
\text { or cell culture }\end{array}$ & $\begin{array}{l}\text { The first test developed for the } \\
\text { laboratory diagnosis of } T \text {. } \\
\text { gondii infection }\end{array}$ \\
\hline $\begin{array}{l}\text { Indirect fluorescent assay } \\
\text { (IFA) }\end{array}$ & $\begin{array}{l}\text { More economical and safer to } \\
\text { perform than DT, measuring } \\
\text { the same antibodies as the DT } \\
\text { Test results are easy to evaluate } \\
\text { visually } \\
\text { IFA has proved to be specific }\end{array}$ & $\begin{array}{l}\text { The interpretation is subjective } \\
\text { and time-consuming } \\
\text { Lower sensitivity compared to } \\
\text { the DT } \\
\text { False-positive results may occur }\end{array}$ & $\begin{array}{l}\text { The IFA requires the use of a } \\
\text { fluorescence microscope }\end{array}$ \\
\hline Direct agglutination test & $\begin{array}{l}\text { The direct agglutination test } \\
\text { needs no special equipment or } \\
\text { conjugates } \\
\text { A sensitive, specific, and useful } \\
\text { assay that shows good } \\
\text { correlation with the DT }\end{array}$ & $\begin{array}{l}\text { Non-specific immunoglobulins } \\
\text { interfere with the test } * \text { (but } \\
\text { they can be removed by } \\
\text { treatment with } \\
\text { mercaptoethanol and } \\
\text { enzymatic treatment) }\end{array}$ & $\begin{array}{l}\text { Measurement of } \mathrm{IgG} \text { antibodies } \\
\text { to Toxoplasma that react with } \\
\text { the membrane antigen }\end{array}$ \\
\hline $\begin{array}{l}\text { Differential agglutination } \\
\text { test (HS/AC test) }\end{array}$ & $\begin{array}{l}\text { The AC antigen preparation } \\
\text { involves stage-specific } \\
\text { antigens that are preferentially } \\
\text { detected by IgG antibodies } \\
\text { formed against Toxoplasma } \\
\text { tachyzoites at the early stages } \\
\text { of infection }\end{array}$ & - & $\begin{array}{l}\text { Sera from individuals with acute } \\
\text { infection tended to agglutinate } \\
\text { both the HS and AC parasite } \\
\text { suspensions } \\
\text { Higher titers in the HS } \\
\text { agglutination test and lower or } \\
\text { negative titers in the AC } \\
\text { agglutination were found in in } \\
\text { cases which acquired infection } \\
\text { in the distant past }\end{array}$ \\
\hline $\begin{array}{l}\text { Latex agglutination test } \\
\text { and indirect } \\
\text { agglutination test (LAT) }\end{array}$ & Easy to perform and sensitive & Issues with its specificity & $\begin{array}{l}\text { The antibody response in acute } \\
\text { infections may not be detected } \\
\text { for many weeks, showing the } \\
\text { predominance of cytoplasmic } \\
\text { antigens present in the assays }\end{array}$ \\
\hline $\begin{array}{l}\text { The immunosorbent } \\
\text { agglutination assay } \\
\text { (ISAGA) }\end{array}$ & $\begin{array}{l}\text { A highly specific test for the } \\
\text { detection of anti-T. gondii } \\
\text { IgM, IgA, or IgE antibodies } \\
\text { One the most sensitive } \\
\text { commercially available } \\
\text { Toxoplasma serologic tests }\end{array}$ & $\begin{array}{l}\text { It requires a high degree of } \\
\text { expertise and is not automated }\end{array}$ & $\begin{array}{l}\text { Used in reference centers, and } \\
\text { usually in neonates suspected } \\
\text { of having a congenital } \\
\text { infection } \\
\text { Also applied for the detection of } \\
\text { IgE and IgA }\end{array}$ \\
\hline $\begin{array}{l}\text { Enzyme immunoassays } \\
\text { (EIA) }\end{array}$ & $\begin{array}{l}\text { The most common laboratory } \\
\text { Toxoplasma diagnostic test } \\
\text { [ELISA and the enzyme-linked } \\
\text { fluorescent immunoassay } \\
\text { (ELFA) are the two most } \\
\text { common EIAs] } \\
\text { Available as commercial kits and } \\
\text { automated platforms } \\
\text { Fast and low-cost screening tests } \\
\text { Improved to avoid false-positive } \\
\text { results }\end{array}$ & $\begin{array}{l}\text { Poor standardization due to } \\
\text { variations in antigen quality } \\
\text { and consequent variable results }\end{array}$ & $\begin{array}{l}\text { The use of recombinant antigens } \\
\text { reduces the cost and labor } \\
\text { required for the production of } \\
\text { diagnostic tests }\end{array}$ \\
\hline
\end{tabular}


Table 1 continued

\begin{tabular}{|c|c|c|c|}
\hline Name of serological test & Advantages & Disadvantages & Special features \\
\hline IgG avidity test & $\begin{array}{l}\text { Used to discriminate recently } \\
\text { acquired infections from those } \\
\text { that occurred in the more } \\
\text { distant past } \\
\text { The presence of high avidity } \\
\text { antibodies is a reliable marker } \\
\text { of chronic infection } \\
\text { Very useful in pregnant women } \\
\text { with positive IgG and IgM } \\
\text { titers at their first antenatal } \\
\text { visit (during the first trimester } \\
\text { of pregnancy) }\end{array}$ & $\begin{array}{l}\text { Further serologic techniques } \\
\text { should be applied when low or } \\
\text { borderline avidity results are } \\
\text { encountered }\end{array}$ & $\begin{array}{l}\text { No universal threshold has been } \\
\text { defined above which avidity is } \\
\text { confirmed to be high (most } \\
\text { laboratories apply their own } \\
\text { interpretation according to } \\
\text { their requirements) }\end{array}$ \\
\hline $\begin{array}{l}\text { Immunochromatographic } \\
\text { tests (ICT) }\end{array}$ & $\begin{array}{l}\text { Point-of-care testing } \\
\text { Cost-effective } \\
\text { User-friendly format } \\
\text { Fast time results }\end{array}$ & Low sensitivity and specificity & Useful as a screening test \\
\hline Western blotting & $\begin{array}{l}\text { Diagnosis congenital infection in } \\
\text { newborns } \\
\text { A highly sensitive and specific } \\
\text { method for the reliable } \\
\text { detection of Toxoplasma } \\
\text { infection as a confirmatory test }\end{array}$ & - & $\begin{array}{l}\text { Very useful for the follow-up } \\
\text { testing of pregnant women and } \\
\text { their infants or for } \\
\text { immunodeficient individuals } \\
\text { after HIV infection, } \\
\text { malignancies, or organ } \\
\text { transplantation }\end{array}$ \\
\hline
\end{tabular}

References: [7, 122-135]

AC antigen, acetone- or methanol-fixed tachyzoites; HIV, human immunodeficiency virus; HS antigen, formalin-fixed tachyzoites; Ig, immunoglobulin

these cases, plays a pivotal role in recognizing vitreoretinal tractions, vitritis, vitreous hemorrhage, retinal holes and retinal detachments. Other pathologies such macular edema, choroidal detachments and optic disk edema can also be observed. Even in the presence of clear media, US is also helpful in excluding severe clinical entities of mass lesion morphology, such as melanoma, retinoblastoma or other intraocular syndromes that manifest in the form of inflammation. Anterior segment complications (e.g., angle-closure glaucoma, detachment of the ciliary body, etc.) can also be detected by US examination [66].

\section{Diagnosis}

Laboratory diagnosis of toxoplasmosis involves several direct and indirect detection methods including amplification of specific nucleic acid sequences in body fluids and tissues by polymerase chain reaction
(PCR), serological methods, immunohistochemical identification of the parasite (i.e., immunoperoxidase stain), in vitro culture and animal inoculation (Table 1). Rarely, detection of the protozoan parasite antigen in serum and body fluids, a toxoplasmin skin test and antigen-specific lymphocyte transformation, has also been used [76, 77]. In cases of diagnostic uncertainty during fundoscopy, laboratory tests can be implemented. The detection of specific antibodies, as well as the PCR-based assays in both aqueous and vitreous fluids, may be effectively used as diagnostic tools in ocular toxoplasmosis [77].

\section{PCR-based assays}

PCR-based assays have become increasingly relevant for the diagnosis of toxoplasmosis due to their remarkable sensitivity and specificity, and the limitations that are usually demonstrated by conventional and serological methods as well. PCR is the main 
detection method to determine $T$. gondii in congenital infections, ocular inflammation, and immunocompromised individuals including organ transplant recipients and HIV-infected patients [78]. Among women with serological evidence of primary infection, PCR is very effective for prenatal diagnosis of congenital toxoplasmosis affecting the amniotic fluid. [79]. In such samples, the specificity and positive predictive value of the PCR-based tests are approximately $100 \%$, whereas the sensitivity varies from 70 to $95 \%$ [80] and appears to be associated with the gestational age and the selected method as well. More specifically, the highest sensitivity is recorded at 17-21 weeks of gestation, in comparison with less significant rates occurring before week 17 or after week 21 of pregnancy [11]. Both monoplex and multiplex PCR methods can be utilized for specifically identifying $T$. gondii in aqueous and vitreous fluids [81]. Interestingly, numerous laboratories have incorporated their in-house PCR methods which are not sufficiently standardized. Thus, there is a substantial range and complexity of different PCR protocols relying considerably on several parameters, including target, primer, applied technology, and the proficiency in optimization of PCR conditions [82]. Real-time PCR, which has been successfully applied as a diagnostic tool in toxoplasmosis, combines the steps of both nucleic acid amplification and PCR product detection in a single phase, providing increased sensitivity and specificity. Moreover, it enables the quantitative measurement of protozoan parasites in amniotic fluid, which may be critical in defining the correlation with the clinical spectrum of disease, therapeutic response, and the assessment of neonatal outcomes [83].

Several studies have been carried out in order to demonstrate the sensitivity and specificity of PCRbased methods. It has been reported that such assays appear to have low false-positive rates when used on ocular fluids, while it is rather difficult to evaluate the false-negative rates since there is no comparable gold standard method other than the clinical diagnosis [84]. Data from a retrospective study showed that sensitivity of a real-time PCR testing in ocular fluid from individuals with possible $T$. gondii infectious uveitis was $57 \%$, but the same results also indicated that PCR method was a valid technique in atypical toxoplasmosis which could not be diagnosed with certainty on clinical manifestations [84].
More recently, a nested-PCR protocol targeting the B1 gene appeared to be highly sensitive in the detection of the protozoan parasite DNA in ocular fluids of toxoplasmosis-infected patients [85]. Today, researchers also use protocols targeting Rep529 instead of B1 gene, due to both higher genome copy numbers and clinical sensitivity in various clinical specimens, including amniotic fluid, placental tissue, cerebrospinal fluid, cord and peripheral blood, while only a few studies have directly compared the aforementioned procedures on intraocular specimens [86]. In such a study, a dual-target (B1, Rep529) realtime PCR applied in intraocular specimens demonstrated $97.2 \%$ positive agreement and $99.1 \%$ negative agreement with a conventional nested-PCR targeting the $\mathrm{B} 1$ gene. The clinical application of this assay on intraocular fluids appears to increase the inclusivity and sensitivity without loss of specificity [86]. Moreover, the molecular assays appear more sensitive in immunosuppressed than immunocompetent patients. According to a study that included immunocompromised and immunocompetent patients with ocular toxoplasmosis, the PCR-based technique revealed higher sensitivity in the first than in the latter group of individuals [87]. This is following previous studies which have reported that $T$. gondii DNA can be amplified by PCR protocols in intraocular fluid samples in $30-40 \%$ and $75 \%$ of the clinically diagnosed cases of ocular toxoplasmosis in immunocompetent and immunocompromised patients, respectively [88]. In a recent review, evaluating the diagnostic value of molecular procedures for the diagnosis of ocular toxoplasmosis in specific patient groups, researchers reported that the sensitivity rates in immunocompromised and immunocompetent patients ranged from 61.5 to $100 \%$ and from 25 to $53 \%$, respectively [89]. Low sensitivity rates in immunocompetent patients are directly related to the fact that when their clinical manifestations first appear, the generation of a potent inflammatory reaction depends on the host's immune response rather than the protozoan parasite's activity [61]. Nevertheless, the sensitivity of molecular procedures relies not only on the immunological status of the patients but on the timely specimen collection after the onset of the symptoms, as well. In such cases, molecular assays have been reported as the most sensitive techniques applied during the first weeks of symptom onset [89]. Regarding the most appropriate 
Table 2 Available drug options for toxoplasmosis

\begin{tabular}{|c|c|c|}
\hline Medication & Adult dose & Pediatric dose \\
\hline Pyrimethamine & $\begin{array}{l}\text { Loading dose: } 100 \mathrm{mg} \text { (1st day) } \\
\text { Treatment dose: } 25 \mathrm{mg} \text { twice daily } \\
\text { for } 4-6 \text { weeks }\end{array}$ & $\begin{array}{l}\text { 1. Infants } \\
1 \mathrm{mg} / \mathrm{kg} \text { once daily for } 1 \text { year } \\
\text { 2. Children } \\
\text { Loading dose: } 2 \mathrm{mg} / \mathrm{kg} / \text { day divided into } 2 \text { daily doses for } 1-3 \text { days } \\
\quad \text { (maximum: } 100 \mathrm{mg} / \text { day) } \\
\text { Treatment dose: } 1 \mathrm{mg} / \mathrm{kg} / \text { day divided into } 2 \text { doses for } 4 \text { weeks; } \\
\text { (maximum: } 25 \mathrm{mg} / \text { day) }\end{array}$ \\
\hline Folinic acid & $15 \mathrm{mg}$ daily & $5 \mathrm{mg}$ every 3 days \\
\hline $\begin{array}{l}\text { Trimethoprime- } \\
\text { sulfamethoxazol }\end{array}$ & $\begin{array}{l}\text { One tablet twice daily for } \\
4-6 \text { weeks }\end{array}$ & 6-12 mg TMP/kg/day in divided doses every $12 \mathrm{~h}$ \\
\hline Sulfadiazine & $4 \mathrm{~g}$ daily divided every $6 \mathrm{~h}$ & $\begin{array}{l}\text { 3. Congenital toxoplasmosis } \\
\text { Newborns and Children }<2 \text { months: } 100 \mathrm{mg} / \mathrm{kg} / \text { day divided every } 6 \mathrm{~h} \\
\text { Children }>2 \text { months: } 25-50 \mathrm{mg} / \mathrm{kg} / \text { dose } 4 \text { times/day } \\
\text { 4. Toxoplasmosis in children }>2 \text { months } \\
\text { Loading dose: } 75 \mathrm{mg} / \mathrm{kg} \\
\text { Treatment dose: } 120-150 \mathrm{mg} / \mathrm{kg} / \text { day, divided every } 4-6 \mathrm{~h} \text { (maximum } \\
\text { dose: } 6 \mathrm{~g} / \text { day) }\end{array}$ \\
\hline Clindamycin & $\begin{array}{l}\text { 150-450 mg/dose every } 6-8 \mathrm{~h} \\
\text { (maximum dose: } 1.8 \mathrm{~g} / \text { day) } \\
\text { (usually } 300 \mathrm{mg} \text { every } 6 \mathrm{~h} \text { ) }\end{array}$ & $8-25 \mathrm{mg} / \mathrm{kg} /$ day in $3-4$ divided doses \\
\hline Azithromycin & $\begin{array}{l}\text { Loading dose: } 1 \mathrm{~g} \text { (1st day) } \\
\text { Treatment dose: } 500 \mathrm{mg} \text { once } \\
\text { daily for } 3 \text { weeks }\end{array}$ & $\begin{array}{l}\text { Children } \geq 6 \text { months: } 10 \mathrm{mg} / \mathrm{kg} \text { on first day (maximum: } 500 \mathrm{mg} / \text { day) } \\
\text { followed by } 5 \mathrm{mg} / \mathrm{kg} / \text { day once daily (maximum: } 250 \mathrm{mg} / \text { day) }\end{array}$ \\
\hline Spiramycin & $2 \mathrm{~g}$ per day in two divided doses & $\begin{array}{l}15 \mathrm{~kg}=750 \mathrm{mg} \\
20 \mathrm{~kg}=1 \mathrm{~g} \\
30 \mathrm{~kg}=1.5 \mathrm{~g}\end{array}$ \\
\hline Atovaquone & $750 \mathrm{mg}$ every $6 \mathrm{~h}$ for $4-6$ weeks & $\begin{array}{l}40 \mathrm{mg} / \mathrm{kg} / \text { day divided twice daily (maximum dose: } \\
1500 \mathrm{mg} / \text { day) }\end{array}$ \\
\hline Tetracycline & $\begin{array}{l}\text { Loading dose: } 500 \mathrm{mg} \text { every } 6 \mathrm{~h} \\
\text { (first day) } \\
\text { Treatment dose: } 250 \mathrm{mg} \text { every } 6 \mathrm{~h} \\
\text { for } 4-6 \text { weeks }\end{array}$ & Children $>8$ years: $25-50 \mathrm{mg} / \mathrm{kg} /$ day in divided doses every $6 \mathrm{~h}$ \\
\hline Minocycline & $\begin{array}{l}100 \mathrm{mg} \text { every } 12 \mathrm{~h} \text { not to } \\
\text { exceed } 400 \mathrm{mg} / 24 \mathrm{~h} \text { for } 4 \\
\text { to } 6 \text { weeks }\end{array}$ & $\begin{array}{l}\text { Children }>8 \text { years } \\
\text { Initial: } 4 \mathrm{mg} / \mathrm{kg} \text { followed by } 2 \mathrm{mg} / \mathrm{kg} / \text { dose every } 12 \mathrm{~h} \text { (Oral, I.V.) }\end{array}$ \\
\hline
\end{tabular}

g, gram; I.V., intravenous, kg, kilogram; mg, milligram, TMP, trimethoprime

Modified from Bonfioli and Orefice [123] and readjusted according to the protocols of the Department of Ophthalmology (Ocular Inflammation Service) of the University Hospital of Ioannina, Greece

clinical samples, blood is not considered as a suitable one for the diagnosis of ocular toxoplasmosis by using PCR; therefore, aqueous and vitreous fluids remain the most suitable clinical specimens for the molecular confirmation of the infection [87]. Besides, the use of vitreous humor should be considered the most suitable specimen to detect $T$. gondii DNA, since it is in contact with the posterior chamber of the eye, where the infection occurs [87], while PCR procedures have been reported as more sensitive tools in the detection of the protozoan parasite DNA in vitreous (97.5\%) than aqueous (81.5\%) fluid [85]. In contrast, 
aqueous humor has been considered the most reliable clinical sample for both local-specific antibodies production and for DNA detection by PCR [90], since it may be acquired more readily and cheaply than the vitreous fluid [84]. Besides, the aqueous tap seems to be a much safer clinical procedure than the vitreous aspiration needle tap, which is mainly applied in severe atypical protozoan infections or complicated cases [85].

\section{Serological methods}

Several serological procedures have been extensively used, including Sabin-Feldman dye test (DT), indirect fluorescent antibody test (IFA), direct agglutination test (DAT), differential agglutination test (HS/AC test), latex agglutination and indirect agglutination tests (LAT), immunosorbent agglutination assay (ISAGA), immunochromatographic tests (ICT), enzyme-linked immunosorbent assay (ELISA), IgG avidity test, and Western blot (WB) analysis [77, 91, 92] (Table 2). However, they are not all routinely performed by most hospital-based clinical laboratories, because of excessive cost, lack of experienced personnel and sensitivity, specificity, and interpretation deficiencies.

Association between clinical findings and antibody detection and characterization contributes to defining whether an infection is chronic or recently acquired [93]. Moreover, most patients, especially immunocompetent individuals and pregnant women, present no symptoms or non-specific symptoms. The detection of different antibody classes in body fluids (mostly serum) can be carried out by using several serological assays. The Sabin-Feldman dye test, has been considered as the gold standard serology test, using live $T$. gondii tachyzoites to detect IgG antibodies, and providing high sensitivity and specificity. However, it is not frequently performed due to the high risk for laboratory-acquired infections. The most applicable method for the detection of specific antibodies is ELISA, which contributes to distinguishing between recent infection and one acquired in the distant past. Such information is critically important for pregnant women; thus, they can start their treatment promptly (if required) or even avoid unnecessary treatment and possible teratogenicity when it comes to chronic infections [94]. It has been well-documented that effective treatment at the early stages of the infection decreases significantly vertical transmission and improves clinical outcomes, whereas prenatal treatment may reduce the risk of neurological comorbidities of congenital toxoplasmosis up to $75 \%$ [95]. The presence of $\mathrm{IgG}$ antibodies is considered a marker of past exposure or ongoing infection, whereas the detection of $\operatorname{IgM}$ antibodies usually indicates a current infection [96]. IgM antibodies can be found approximately one week after the onset of infection, and they may remain detectable for months or years after the acute infection [65]. In many cases, detecting IgM antibodies in human serum alone is inadequate for setting a diagnosis of acute toxoplasmosis. Apart from IgM antibodies, IgA, IgE, and IgG are produced during acute infection. In comparison with IgM antibodies, detection of specific $\operatorname{IgA}$ antibodies is considered as a more sensitive marker for diagnosis of acute toxoplasmosis, since they persist for a shorter period after the onset of infection. In addition, IgE antibodies also demonstrate short kinetics and may be more considerably suggestive of current infection; however, they are usually applied complementary to confirm the infections detected by other sensitive methods [97]. IgG antibodies appear in the second week of infection, climax in six to eight weeks, then gradually decline over the next two years, and remain detectable for life. The detection of specific Toxoplasma IgG antibodies suggests the occurrence of infection but cannot provide any information about the timing of infection [93].

The affinity of $\mathrm{IgG}$ antibodies to the antigen is measured by IgG avidity test, which is initially low after infection but increases over time. In particular, the increase from low-to-high avidity is recorded by the sixth month of infection. Therefore, the presence of high avidity antibodies shows that the infection is older than three to five months. However, low or equivocal avidity antibodies can persist for up to one year or even longer and must not be interpreted as a clue of recent infection [93]. Recently acquired infections are typically defined with rising $T$. gondiispecific IgG with low avidity, whereas IgM, IgA and IgE are usually elevated. On the other hand, the chronic phase of the disease may be accompanied by lower IgG titers with high avidity, whereas $\operatorname{IgM}$ and IgA are low or absent.

Regarding congenital toxoplasmosis, IgG antibodies are passively transmitted to the fetus, and therefore their diagnostic value is low. IgG titers drop gradually 
a

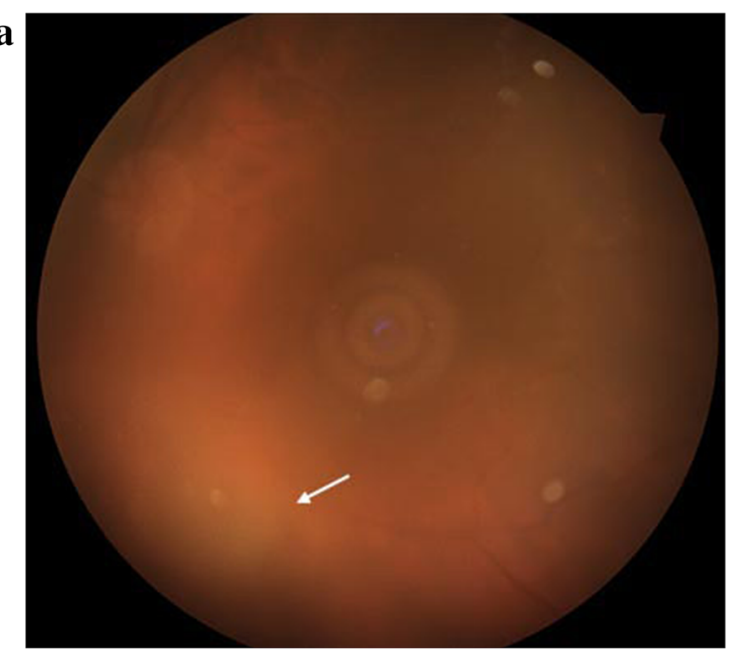

b

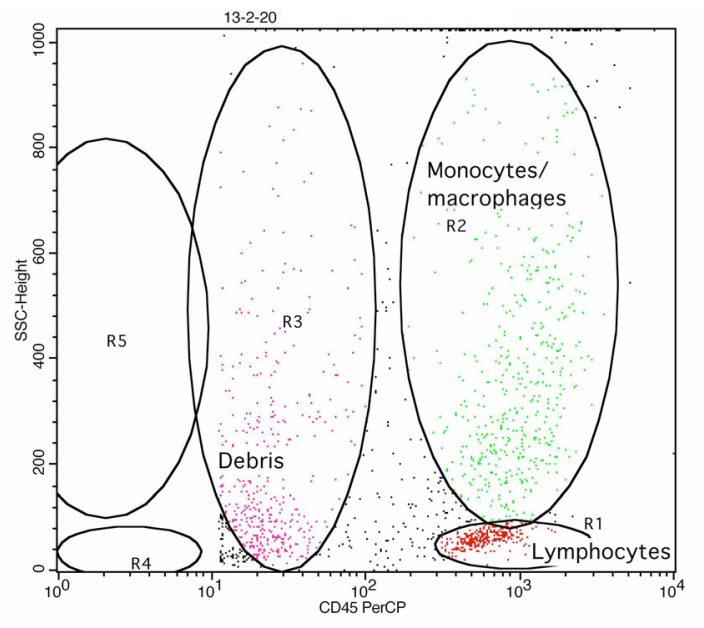

c
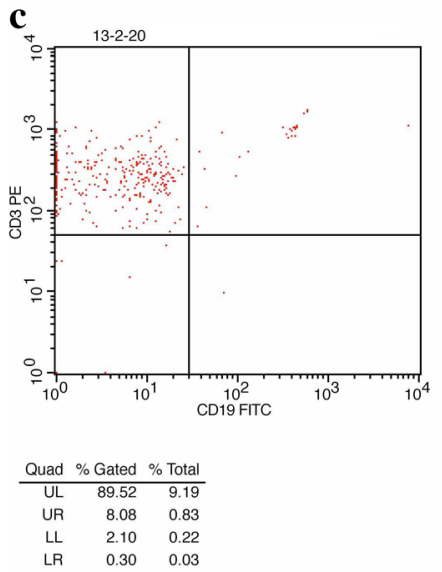

d

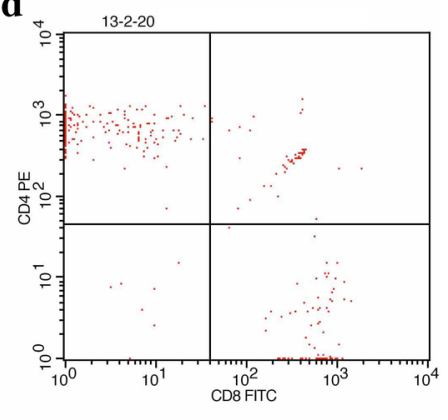

\begin{tabular}{crr} 
Quad & $\%$ Gated & $\%$ Total \\
\hline UL & 56.62 & 10.96 \\
UR & 15.89 & 3.08 \\
LL & 2.65 & 0.51 \\
LR & 24.83 & 4.81
\end{tabular} 
4Fig. 7 A 67-year-old lady with positive serology for toxoplasma (IgM and IgG both positive) with intense and resistant to the treatment inflammation. Taking into consideration the age of the patient the possibility of primary vitreoretinal lymphoma was ruled out using vitreous flow cytometry. a Lesion of acute toxoplasmic retinochoroiditis (white arrow) and dense vitritis obscuring the fundus details. b-d Representative plots of immunophenotyping by three color analysis flow cytometry. It is possible accurately to distinguish lymphocytes from other leukocyte and other cells populations in vitreous humor using the combination of fluorescence associated with CD45 PerCP/ SSC and orthogonal light scatter. By identifying the cell population of interest based on immunofluorescence, a light scattering window can then be drawn to include all ( $\geq 95 \%)$ of the lymphocytes (Gate 1). In this manner, maximal recovery of the lymphocytes within a sample can be consistently obtained. The combination of light scattering and immunofluorescence can also be used to define the purity of the gate. The identification of non-lymphocytes (CD45PerCP negative) within the light scattering gate can then be used to establish an accurate denominator for the percent lymphocytes stained with CDs. b Bivariate histogram CD45/SSC with three gates: gate R1 including lymphocytes (red), gate R2 monocytes and macrophages (green), gate R3 Debris (non-leukocytes, apoptotic /necrotic cells) (purple). c Bivariate histogram CD3 PE/ CD19 FITC in the R1 gate of Lymphocytes: T-Lymphocytes $\mathrm{CD} 3+(95 \%)$, B- Lymphocytes CD19 + (00\%). d Bivariate histogram CD4 PE/CD8 FITC in the R1 gate of Lymphocytes: T helper cells $\left(\mathrm{T}_{\mathrm{h}}\right.$ cells) CD $4+(57 \%), \mathrm{T}$ cytotoxic $\left(\mathrm{T}_{\mathrm{c}}\right.$ cells $)$ $\mathrm{CD} 8+(25 \%)$, and double positive T-cells $\mathrm{CD} 4+\mathrm{CD} 8+(14 \%)$

over the first 18 months. Congenital infection is characterized by persistence or elevation in IgG titers. Increased IgM, IgA and IgE titers in newborns are also correlated with a recent infection [93]. Therefore, the first antenatal serology screening may be ideally performed in the early stages of pregnancy (during gestational week 8-12), and if Toxoplasma-specific IgM titers remain stable and IgG avidity are detected low in a second sample after three to four weeks, the pregnant should probably be advised to have an amniocentesis performed. Nevertheless, these findings do not indicate that the infection occurred during the last three months, since both interpretation and evaluation of the $\operatorname{IgG}$ avidity results are usually associated with the type of the chosen assay and cutoff values, as no gold standard procedure exists [96].

Patients with ocular toxoplasmosis are usually found to have low IgG and negative IgM serum titers, and considering the high rate of seropositive cases in several populations, positive $\mathrm{IgG}$ is not enough to confirm the diagnosis. However, in some cases, $T$. gondii $\operatorname{IgG}$ titers are shown to be higher on average in patients with ocular toxoplasmosis when compared to those with non-toxoplasmic uveitis [98]. In agreement with these findings, it has been reported that the exclusive performance of an immunoenzymatic assay can be useful to confirm active ocular toxoplasmosis and support the clinical diagnosis up to $96 \%$ of typical and atypical cases, by showing both positivity and a significant elevation of specific antibodies titers [99]. As previously detailed, primary or recurrent toxoplasmic retinochoroiditis may be either congenital or acquired. According to an observational study, patients with inactive chronic disease presenting active ocular lesions, positive IgG, and negative IgM serum titers were detected with blood parasitemia which might result in the propagation of the infection. Interestingly, in the absence of active retinal lesions or scars, subclinical parasitemia might be present in seropositive (both $\operatorname{IgG}$ and $\operatorname{IgM}$ ) participants due to reactivated ocular infection or to recurrent ocular lesions at different anatomical locations that were reactivated or clinically underestimated [100]. Falsenegative results are also possible, but in general, a negative serology in immunocompetent patients should exclude toxoplasmosis from the differential diagnosis [93]. Nevertheless, in cases of diagnostic uncertainty, ocular tissues and fluids should be obtained for protozoan parasite detection by PCR or/ and serological tests. ELISA has been considered the "gold standard" method for laboratory confirmation of clinically diagnosed ocular toxoplasmosis. Nevertheless, the sensitivity and specificity of intraocular $T$. gondii antibody detection have been estimated at $63 \%$ and $89 \%$, respectively, since the small volume of the withdrawn sample, and the massive blood-aqueous barrier rupture has been recognized as limitations to the detection of specific antibodies in ocular fluids in immunocompetent individuals $[88,101]$. On the other hand, ocular antibody production is often unpredictable in immunocompromised patients [102]. A positive PCR result should confirm the diagnosis, but in the occurrence of a negative result, the evaluation of antibodies titers in aqueous humor and serum, by the Goldmann-Witmer coefficient (GWC) may be calculated, based on the determination of the specific versus total IgG levels in both aqueous humor and serum. A GWS ratio higher than 1 usually indicates intraocular-specific antibodies production; however, this may be a common finding in healthy individuals, too [102]. 
Table 3 Available drug options for toxoplasmosis

\begin{tabular}{|c|c|c|}
\hline Medication & Adult dose & Pediatric dose \\
\hline Pyrimethamine & $\begin{array}{l}\text { Loading dose: } 100 \mathrm{mg} \text { (1st day) } \\
\text { Treatment dose: } 25 \mathrm{mg} \text { twice daily for } \\
\text { 4-6 weeks }\end{array}$ & $\begin{array}{l}\text { Infants } \\
1 \mathrm{mg} / \mathrm{kg} \text { once daily for } 1 \text { year } \\
\text { Children } \\
\text { Loading dose: } 2 \mathrm{mg} / \mathrm{kg} / \text { day divided into } 2 \text { daily doses for } \\
1-3 \text { days (maximum: } 100 \mathrm{mg} / \text { day) } \\
\text { Treatment dose: } 1 \mathrm{mg} / \mathrm{kg} / \text { day divided into } 2 \text { doses for } 4 \text { weeks; } \\
\text { (maximum: } 25 \mathrm{mg} / \text { day) }\end{array}$ \\
\hline Folinic acid & 15 mg daily & $5 \mathrm{mg}$ every 3 days \\
\hline $\begin{array}{l}\text { Trimethoprime- } \\
\text { sulfamethoxazol }\end{array}$ & One tablet twice daily for $4-6$ weeks & $6-12 \mathrm{mg}$ TMP/kg/day in divided doses every $12 \mathrm{~h}$ \\
\hline Sulfadiazine & $4 \mathrm{~g}$ daily divided every $6 \mathrm{~h}$ & $\begin{array}{l}\text { Congenital toxoplasmosis } \\
\text { Newborns and Children }<2 \text { months: } 100 \mathrm{mg} / \mathrm{kg} / \text { day divided } \\
\text { every } 6 \mathrm{~h} \\
\text { Children }>2 \text { months: } 25-50 \mathrm{mg} / \mathrm{kg} / \text { dose } 4 \text { times/day } \\
\text { Toxoplasmosis in children }>2 \text { months } \\
\text { Loading dose: } 75 \mathrm{mg} / \mathrm{kg} \\
\text { Treatment dose: } 120-150 \mathrm{mg} / \mathrm{kg} / \text { day, divided every } 4-6 \mathrm{~h} \\
\text { (maximum dose: } 6 \mathrm{~g} / \mathrm{day} \text { ) }\end{array}$ \\
\hline Clindamycin & $\begin{array}{l}150-450 \mathrm{mg} / \text { dose every } 6-8 \mathrm{~h} \text { (maximum } \\
\text { dose: } 1.8 \mathrm{~g} / \text { day) (usually } 300 \mathrm{mg} \text { every } \\
6 \mathrm{~h} \text { ) }\end{array}$ & $8-25 \mathrm{mg} / \mathrm{kg} /$ day in $3-4$ divided doses \\
\hline Azithromycin & $\begin{array}{l}\text { Loading dose: } 1 \mathrm{~g} \text { (1st day) } \\
\text { Treatment dose: } 500 \mathrm{mg} \text { once daily for } \\
3 \text { weeks }\end{array}$ & $\begin{array}{l}\text { Children } \geq 6 \text { months: } 10 \mathrm{mg} / \mathrm{kg} \text { on first day (maximum: } \\
500 \mathrm{mg} / \text { day) followed by } 5 \mathrm{mg} / \mathrm{kg} / \text { day once daily (maximum: } \\
250 \mathrm{mg} / \text { day) }\end{array}$ \\
\hline Spiramycin & $2 \mathrm{~g}$ per day in two divided doses & $\begin{array}{l}15 \mathrm{~kg}=750 \mathrm{mg} \\
20 \mathrm{~kg}=1 \mathrm{~g} \\
30 \mathrm{~kg}=1.5 \mathrm{~g}\end{array}$ \\
\hline Atovaquone & $750 \mathrm{mg}$ every $6 \mathrm{~h}$ for $4-6$ weeks & $40 \mathrm{mg} / \mathrm{kg} /$ day divided twice daily (maximum dose: $1500 \mathrm{mg} /$ day) \\
\hline Tetracycline & $\begin{array}{l}\text { Loading dose: } 500 \mathrm{mg} \text { every } 6 \mathrm{~h} \text { (first day) } \\
\text { Treatment dose: } 250 \mathrm{mg} \text { every } 6 \mathrm{~h} \text { for } \\
4-6 \text { weeks }\end{array}$ & Children $>8$ years: $25-50 \mathrm{mg} / \mathrm{kg} /$ day in divided doses every $6 \mathrm{~h}$ \\
\hline Minocycline & $\begin{array}{l}100 \mathrm{mg} \text { every } 12 \mathrm{~h} \text { not to exceed } 400 \mathrm{mg} / \\
24 \mathrm{~h} \text { for } 4 \text { to } 6 \text { weeks }\end{array}$ & $\begin{array}{l}\text { Children }>8 \text { years } \\
\text { Initial: } 4 \mathrm{mg} / \mathrm{kg} \text { followed by } 2 \mathrm{mg} / \mathrm{kg} / \text { dose every } 12 \mathrm{~h} \text { (Oral, I.V.) }\end{array}$ \\
\hline
\end{tabular}

g, gram; I.V., intravenous; kg, kilogram; mg, milligram; TMP, trimethoprime

Modified from: Bonfioli and Orefice [99] and readjusted according to the protocols of the Department of Ophthalmology (Ocular Inflammation Service) of the University Hospital of Ioannina, Greece

Therefore, a GWS ratio higher than 2 or at least 3 is considered positive confirming the diagnosis $[88,90,102]$. The sensitivity of GWC is estimated at $50 \%[103,104]$ and regarding immunocompromised and immunocompetent patients, 57\% and 93\%, respectively [105]. In addition, if the GWC is not able to differentiate between locally produced and systemic antibodies, WB analysis of serum and paired aqueous humor sampled the same day can be effectively performed. WB analysis has shown equal sensitivity and higher specificity (>95\%) than GWC and is less affected by the rupture of the blood-retinal barrier [106]. Nevertheless, the sensitivity depends on the interval between symptom onset and paracentesis. In a recent retrospective study, when the aqueous humor was taken in the first three weeks after 
symptom onset, the sensitivity of WB was significantly higher than GWS (64.7\% vs $23.5 \%)$, while the sensitivity rates were not remarkably differentiated in cases with an interval $>3$ weeks $(76 \%$ and $64 \%$, for WB and GWC, respectively [107]. Antibodies may be detected in bands between 20- and $120-\mathrm{kDa}$ on immunoblotting assays [108]. It has been reported that the combination of PCR, GWC, and WB contributes to establishing a relevant ocular toxoplasmosis diagnosis by providing high sensitivity and specificity [88]. In such a study, the diagnostic sensitivity was reported $92 \%$ for the GWC-WB, $90 \%$ for the WB-PCR, and $93 \%$ for the GWC-PCR combinations, while performing all methods together, increased the sensitivity to $97 \%$ [90]. The assessment of aqueous humor is further supported by $\operatorname{IgM}$ and $\operatorname{IgA}$ evaluation [43, 106, 109]. In a recent study, IgM and IgA antibodies were detected in immunocompetent patients with acute ocular toxoplasmosis, in combination with positive PCR results. Interestingly, after the treatment used, both serological IgM profile and the result of PCR were modified, in contrast with the serological IgG and IgA profiles, which may act as suitable markers to follow-up the patients [110]. In overall, combining PCR (especially in immunocompromised individuals) and antibody detection in the aqueous humor is substantial in setting a diagnostic, especially in atypical cases.

\section{Interferon gamma IFN- $\gamma$ release assay}

Toxoplasmosis results in long-term cell-mediated immunity which is dependent on the production of interferon gamma (IFN- $\gamma$ ) by T-lymphocytes. On this basis, an easily performed whole blood IFN- $\gamma$ release assay has been introduced as a candidate for a diagnosis of Toxoplasma infection [111, 112]. The sensitivity and specificity rates in seropositive adults with either acute or chronic infection have been reported $96 \%$ and $91 \%$, respectively, while in infants born from mothers who were infected during pregnancy, the assay yielded a sensitivity and specificity of $94 \%$ and $98 \%$, respectively [111]. In another study analyzing the secretion of IFN- $\gamma$ in chronic toxoplasmic patients with or without ocular involvement, results demonstrated higher levels of IFN- $\gamma$ in the latter than in the former group of individuals, indicating the weak resistance to develop ocular lesions [113].

\section{Differential diagnosis}

T. gondii-specific IgG antibodies are detected in the majority of typical clinical cases, suggesting a past infection (either congenital or postnatally acquired). However, taking into consideration the high seroprevalence of IgG antibodies in most countries, the determination of this specific serologic marker is simply considered confirmatory [114]. Even though the absence of $\operatorname{IgG}$ antibodies almost rules out the possibility of ocular disease, false-negative results can be also observed in rare cases [115]. Therefore, it is important to combine various serological test systems in individuals with typical fundus findings but negative IgG test results. A large number of atypical clinical manifestations of recently acquired ocular toxoplasmosis may also exist (e.g., large active lesions without a scar). In these cases, laboratory confirmation is essential for defining the etiology of the disease [116]. On the other hand, setting a pure clinical diagnosis may be challenging as other causes of uveitis, such as toxocariasis, multifocal choroiditis, punctate inner choroidopathy (PIC), acute posterior multifocal placoid pigment epitheliopathy (APMPPE) histoplasmosis (POHS), acute retinal necrosis syndrome (herpes simplex virus, varicella zoster virus), tuberculosis, sarcoidosis, serpiginous choroiditis, syphilis, endophthalmitis, and ocular lymphoma may present with some clinical features of toxoplasmic retinochoroiditis [49, 93]. In such cases, further laboratory testing is required to detect other candidate pathogens. In particular, vitreoretinal lymphoma may in cases with positive IgG serum toxoplasma antibodies masquerade as toxoplasmic uveitis. On the other hand, a severe toxoplasmic uveitis with dense vitritis in the elderly also may be an opportunistic infection with underlying disease a primary central nervous system lymphoma (Fig. 7a-d). In those cases, vitreous flow cytometry and central nervous system MRI are necessary to rule out intraocular lymphoma.

\section{Treatment}

Treatment of ocular toxoplasmosis remains controversial. Some clinicians do not treat small peripheral retinal lesions, while others treat all patients in order to reduce recurrences and complication rates. Typically, toxoplasmic retinochoroiditis in immunocompetent patients is expected to resolve within 1 to 2 months 
[117]. Taking into account the benign natural course and the possibility of toxicity to the antiparasitic drugs, the therapeutic approach of each individual with active infection would probably lead to unnecessarily high rates of drug-induced morbidity. Subsequently, treatment is adjusted to each patient individually. The decision of commencing treatment in cases of active retinochoroiditis is based on several parameters. Some of the most important are the following:

- Patients' immune status

- Characteristics of the active lesion (i.e., location and size)

- Visual acuity

- Clinical course

- Grading of vitreous haze

- Macular edema

- Edema of the optic disk

- Vascular occlusion

- Possible adverse effects of available drugs

- Other parameters (newborns, pregnancy, allergies).

The treatment of ocular toxoplasmosis includes both antimicrobial drugs (Table 3 ) and corticosteroids (topical and oral) and is maintained for 4-6 weeks. The main target of the antimicrobial treatment at the stage of active retinitis is to control the parasites' multiplication [118]. Currently, the number of randomized control trials in the setting of toxoplasmic retinochoroiditis is restricted [119]. Another issue regarding the therapeutic approach of chronic infections is the fact that antiparasitic drugs may be ineffective against tissue cysts [120].

The first choices include one of the following combination regimens: (1) pyrimethamine, sulfadiazine, folinic acid and prednisone; (2) pyrimethamine, clindamycin, folinic acid and prednisone; (3) pyrimethamine, sulfadiazine, clindamycin, folinic acid and prednisone. Trimethoprim-sulfamethoxazole can also be a good alternative of sulfadiazine concerning first choice combination regimens. Alternative combination regimens include: (1) trimethoprim-sulfamethoxazole and prednisone; (2) clindamycin, spiramycin, and prednisone; (3) clindamycin, sulfadiazine, and prednisone; (4) pyrimethamine, azithromycin, folinic acid and prednisone; (5) pyrimethamine, atovaquone, folinic acid and prednisone; (6) sulfadiazine, atovaquone and prednisone; (7) tetracycline and prednisone; (8) minocycline and prednisone [93, 121].
The exact therapeutic drug regimens are summarized in Table 2.

The 'classic therapy' consists of pyrimethamine, sulfadiazine and a systemic corticosteroid (most commonly prednisone) [122]. It was found that none of three therapies (i.e., Classic therapy; Clindamycin with sulfadiazine and oral steroid; Trimethoprim with sulfamethoxazole and oral steroid) reduced the duration of posterior pole retinitis compared to control subjects with peripheral lesions that received no treatment [118]. Additionally, treatment did not affect the rates of recurrence. However, it was shown that the classic regimen was more effective in the reduction of the size of the lesion(s) in comparison with treatments or no treatment. The same study reported that the classic treatment may be more suitable for foveal or adjacent to the fovea lesions. [118].

The use of pyrimethamine and sulfadiazine for treating ocular toxoplasmosis was introduced in the 1950s [28]. The possibility of medication-related adverse events (including gastrointestinal and dermatological side effects, leukopenia and thrombocytopenia) should always be taken into account. Therefore, blood testing should be carried out every week throughout treatment and folinic acid must be also prescribed [48]. Sulfadiazine is a sulfonamide antimicrobial that can cause hypersensitivity reactions, such as skin rashes.

Trimethoprim-sulfamethoxazole is defined by good tolerability, wide availability and low cost. However, sulfonamide-related reactions may occur [122]. Trimethoprim-sulfamethoxazole with prednisone was found to be relatively well-tolerated, but as effective as the classic therapy in the reduction in lesions' size [118]. In contrast, a relevant study reported comparable outcomes among trimethoprimsulfamethoxazole with prednisolone and classic therapy in two randomized groups [123]. Additionally, the role of trimethoprim-sulfamethoxazole in preventing the recurrences of toxoplasmic retinochoroiditis calls for further investigation [124].

Clindamycin can be added to the triple regimen, converting it to 'quadruple therapy' [122], which has been found to improve vision and/or intraocular inflammatory markers [125]. On the contrary, Rothova et al. [118] reported a smaller reduction in lesion size in those treated with clindamycin, sulfadiazine and corticosteroid compared to the classic therapy. Pseudomembranous colitis can be caused by clindamycin, 
and diarrhea consists an indication for cessation of the drug. The intravitreal use of clindamycin and dexamethasone has been also assessed by recent studies. [126-129]. A substantially larger reduction in size of lesions was found in $T$. gondii IgM-positive patients who were treated with classic treatment in comparison with those who received intravitreal treatment [129]. Topical treatment seems to be suitable for individuals with recurrent infection, due to the concerns regarding systemic drug toxicities. On the other hand, this approach would not be recommended in patients with immunodeficiency (e.g., HIV-patients) due to the risk of fulminant disease [130]. Intravitreal treatment (1 mg clindamycin with or without $400 \mu \mathrm{g}$ dexamethasone) [128] may also be necessary in cases with fovea involvement or active lesion(s) within zone 1 as an adjunctive to systemic therapy [129, 131].

Two other antiparasitic drugs, atovaquone and azithromycin [93, 122], were found to have promising results in experimental studies, but do not show favorable outcomes in preventing recurrences of retinochoroiditis in humans.

The comparison of the efficacy of classic therapy and pyrimethamine plus azithromycin showed no difference between the two groups but the adverse events in those treated with azithromycin were less frequent and less severe [132].

Although their benefit has been completely delineated, systemic steroids can be added to the therapeutic regimen against toxoplasmic retinochoroiditis. However, the doses prescribed and timing of administration may widely differ among uveitis specialists. Corticosteroids are usually initiated 3 days after the start of antibiotic therapy and must be suspended at least 10 days before the antimicrobial drugs [133]. If given without antimicrobials (e.g., in cases of initial misdiagnosis or atypical presentation), systemic steroids can lead to legal blindness in most patients [133]. Systemic corticosteroids are usually avoided in immunocompromised patients [122]. This category of patients is treated with a maintenance antimicrobial therapy while being immunocompromised (e.g., trimethoprim-sulfamethoxazole). Periocular corticosteroid injections are generally unpopular [122], as their administration has been correlated to detrimental results, especially in patients that have not received an antiparasitic therapy [134]. Intravitreal administration of relatively short-acting dexamethasone has been successfully combined with clindamycin. Intravitreal injection of triamcinolone acetonide, which is longer acting, has not been widely practiced [135], and therefore, there is no standard consensus on this approach [136].

Steroid eye drops are widely prescribed for controlling anterior uveitis [122]. Their frequency depends on the severity of inflammatory activity in the anterior segment. Apart from topical steroids, mydriatics and hypotensive agents are also added when required. Mydriatics are important for the prevention of posterior synechiae (or breaking them if they have already developed) and for pain relief.

Immunocompromised patients are treated with the antimicrobial regimens described above, for 6 or more weeks. After complete resolution of the lesions, the patient starts on secondary prophylaxis, with sulfadiazine, pyrimethamine and folinic acid or clindamycin, pyrimethamine and folinic acid. In asymptomatic individuals with a CD4 count above 200 cells/ $\mu \mathrm{L}$ for six months or more, prophylaxis for toxoplasmosis can be stopped, but patients must be followed up for detecting signs of recurrence [93]. In HIV patients with toxoplasmic retinochoroiditis, neuroimaging is crucial to rule out central nervous system (CNS) toxoplasmosis lesions. Treatment includes ongoing suppressive therapy with pyrimethamine and sulfadiazine [137].

In pregnancy, the highest risk regarding the adverse effects of antiparasitic drugs is during the first trimester [138]. Consequently, a multidisciplinary assessment between the ophthalmologist, the obstetrician and an infectious disease physician is vital in cases where an intervention is required. A serological investigation is necessary in women with toxoplasmic chorioretinitis during pregnancy, to define when the infection was acquired. Reactivation of a latent infection (acquired before gestation) leading to toxoplasmic chorioretinitis does not present a higher risk for transmission of $T$. gondii to their offspring compared to pregnant women with an acquired infection before gestation but no signs of active ocular toxoplasmosis [139]. When a toxoplasmic retinochoroiditis is attributed to a recently acquired infection, treatment must be administered not only for treating the ophthalmic disease but also for reducing the risk of transmission to the fetus [140]. During pregnancy, the therapeutic regimens are: (1) First trimester: spiramycin, and sulfadiazine; (2) Second trimester ( $>14$ weeks): spiramycin, sulfadiazine, 
pyrimethamine, and folinic acid; (3) Third trimester: spiramycin, pyrimethamine and folinic acid. Medications are given in lower doses for three weeks and can be repeated, if required, after 21 days [121]. Moreover, treating the mother lessens the possibility of congenital transmission. Classic therapy is contraindicated as pyrimethamine is considered to be teratogenic and sulfadiazine can cause bilirubin encephalopathy [141]. Clindamycin and azithromycin or clindamycin and atovaquone ( \pm systemic corticosteroid) are discussed as alternatives [141]. The recurrences of toxoplasmic retinochoroiditis pose minimal risk to the embryo. Thus, preventing vertical transmission alone is not an indication for treatment [142]. When a toxoplasmic infection occurs during or immediately before pregnancy, the risk of transmission to the fetus and congenital toxoplasmosis is significantly higher. This condition requires coordinated management together with a perinatologist, for a more detailed approach, the reader is referred to the study of Montoya and Remington [140]. The severity of toxoplasmic retinochoroiditis is multifactorial and varies widely in different geographical areas. Due to the increased risk of detrimental intraocular complications, the lack of large controlled studies does not justify changes to the standard therapy for this clinical entity. Two surveys of the American Uveitis Society (AUS), in 1991 [143] and 2001 [122], highlighted a substantial shift in favor of treating both mild and severe disease [122]. Atypical presentations and immunocompromisation are considered as an indication for commencing treatment [44]. Well-designed large interventional studies are required to shed more light on the therapeutic approach of ocular toxoplasmosis.

\section{Course of the disease and prognosis}

The course of ocular toxoplasmosis depends not only on the frequency of recurrences but also on the immediate commencing of the appropriate treatment during active disease in order to minimize the retinal destruction [1]. It has been reported that after an active episode of retinochoroiditis attributed to toxoplasmosis, a recurrence may be observed in up to $79 \%$ of patients during a 5-year follow-up, whereas the mean time between two recurrences varies from 2 months to 25 years [41]. The same study showed that active episodes are expected to occur between 15 and
45 years of age, with a peak at the age of 25 years. Recurrences can occur at the fellow eye but when observed at the same eye they are typically located near an older scarred lesion [41]. The rate of recurrences decreases over time, as the relative risk for a recurrence dropped by $72 \%$ each decade after an active episode [125]. Due to the existence of multiple influences on the severity of the disease, multivariate analysis is crucial. It appears that age and duration of infection are linked with the manifestations of the disease. Moreover, a better understanding of timedependent factors is required. Particularly, the methods of studying the rates of recurrence are studied need to be very carefully assessed [144].

\section{Prevention}

For several years, the vast majority of programs for the prevention of infection have been focused on pregnant women. [144]. However, our current knowledge indicates intraocular inflammations are mostly acquired postnatally [29], and greater emphasis should be given on preventing these cases as well. Since intraocular infections may be subclinical, the visionthreatening disease may manifest several years later, showing the importance of establishing efficient means of preventing ocular disease. Primary prophylactic measures are extremely critical especially not only for seronegative females before and during pregnancy, but also for immunosuppressed patients [122]. Prevention measures also comprise:

- Avoiding consumption of raw/undercooked meat

- Ensuring the provision of well-filtered water;

- Rinsing vegetables/fruits before eating;

- Protected manipulation of meat or soil (e.g., gloves and hand hygiene afterward)

- Avoiding contact with felines and their feces (even in soil/litter boxes)

- Serologic screening during pregnancy in susceptible individuals

With regard to the screening for congenital toxoplasmosis, it was found that universal prenatal screening, even in countries with low prevalence, universal may be cost-saving [145]. Taking into consideration the estimates of lifetime healthcare costs due to developmental disabilities to unborn babies (e.g., loss of vision and neurological damage), 
the importance of these results may be even more crucial for endemic areas [146].

In terms of secondary prevention in immunocompetent adults, sulfamethoxazole/trimethoprim (800/ $160 \mathrm{mg}$ three times per week) decreases the risk of retinochoroiditis recurrences [147], especially in cases with multiple recurrences affecting the macula, and also in those with persistent immunosuppression [124]. However, the ideal duration of this prophylactic treatment is yet to be defined.

\section{Conclusions}

Ocular toxoplasmosis is the most frequent cause of infectious posterior uveitis, and the diagnosis depends largely on the recognition of typical clinical findings. The analysis of serum or intraocular fluids for antibody detection can be used for laboratory confirmation. However, PCR has been gradually more widely used for the detection of the parasite DNA in ocular samples, whereas the sensitivity of this method has significantly increased. Toxoplasmic retinochoroiditis remains a significant cause of loss of vision in many countries with a tremendous impact on the quality of life. However, recent developments in the diagnostic and therapeutic approach have contributed to preventing or limiting vision loss from ocular toxoplasmosis. Oral pyrimethamine, sulfadiazine (or trimethoprim-sulfamethoxazole), and corticosteroids remain the current therapeutic mainstay but other regimens are also effective. More studies are expected to provide a better understanding of epidemiology, pathogenesis, diagnosis and treatment with a significant impact on the management of this challenging clinical entity.

Acknowledgements Special thanks to Ms. Kalliopi Zoumpa (Secretary of Professor C. Kalogeropoulos) for her valuable assistance in the collection of imaging data from our archives.

Authors' contribution All authors participated in the planning, research and writing of the final manuscript, as well as reviewing and rewriting of the revised version.

Data availability All data generated or analyzed during this study are included in this published article (and its supplementary information files).

\section{Declarations}

Conflict of interest The authors declare that they have no conflict of interest.

\section{References}

1. Delair E, Latkany P et al (2011) Clinical manifestations of ocular toxoplasmosis. Ocul Immunol Inflamm 19(2):91-102.

2. Vallochi AL et al (2008) Molecular markers of susceptibility to ocular toxoplasmosis, host and guest behaving badly. Clin Ophthalmol 2(4):837-48.

3. Soheilian M, Heidari K, Yazdani S et al (2004) Patterns of uveitis in a tertiary eye care center in Iran. Ocul Immunol Inflamm 12(4):297-310

4. Balasundaram MB, Andavar R, Palaniswamy $M$ et al (2010) Outbreak of acquired ocular toxoplasmosis involving 248 patients. Arch Ophthalmol 128(1):28-32

5. Atmaca LS, Simsek T, Batioglu F (2004) Clinical features and prognosis in ocular toxoplasmosis. Jpn J Ophthalmol 48(4):386-391

6. Black MW, Boothroyd JC (2000) Lytic cycle of Toxoplasma gondii. Microbiol Mol Biol Rev 64(3):607-623

7. Pleyer U, Schlüter D, Mänz M (2014) Ocular toxoplasmosis: recent aspects of pathophysiology and clinical implications. Ophthalmic Res 52(3):116-123

8. Montoya JG, Liesenfeld O (2004) Toxoplasmosis. Lancet 363(9425):1965-1976

9. Holland GN. Ocular toxoplasmosis: a global reassessment: part I-epidemiology and course of disease. Am J Ophthalmol. 2003;136(6):973-88.

10. Kirby T (2012) Calls for more detailed studies on toxoplasmosis. Lancet Infect Dis 12(12):912-913

11. Dubey JP, Jones JL (2008) Toxoplasma gondii infection in humans and animals in the United States. Int J Parasitol 38(11):1257-1278

12. Kijlstra A, Jongert E (2009) Toxoplasma-safe meat: close to reality? Trends Parasitol 25(1):18-22

13. Tenter AM, Heckeroth AR, Weiss LM (2000) Toxoplasma gondii: from animals to humans. Int $\mathrm{J}$ Parasitol 30(12-13):1217-1258

14. Zhou DH, Zhao FR, Lu P et al (2012) Seroprevalence of Toxoplasma gondii infection in dairy cattle in southern China. Parasit Vectors 5:48

15. Wu D, Lv R, Sun X et al (2012) Seroprevalence of Toxoplasma gondii antibodies from slaughter pigs in Chongqing. China Trop Anim Health Prod 44(4):685-687

16. Dolgikh TI, Zaparii NS, Kadtsyna TV et al (2008) Epidemiological and clinicoimmunological monitoring of toxoplasmosis in the Omsk region (in Russian). Med Parazitol (Mosk) 1:19-22

17. Bowie WR, King AS, Werker DH et al (1997) Outbreak of toxoplasmosis associated with municipal drinking water. The BC Toxoplasma Investigation Team Lancet 350(9072):173-177

18. de Moura L, Bahia-Oliveira LM, Wada MY et al (2006) Waterborne toxoplasmosis, Brazil, from field to gene. Emerg Infect Dis 12(2):326-329

19. Meerburg BG, Kijlstra A (2009) Changing climate changing pathogens: Toxoplasma gondii in North-Western Europe. Parasitol Res 105(1):17-24

20. Feustel SM, Meissner M, Liesenfeld O (2012) Toxoplasma gondii and the blood-brain barrier. Virulence 3(2):182-192 
21. Lachenmaier SM, Deli MA, Meissner M et al (2011) Intracellular transport of Toxoplasma gondii through the blood-brain barrier. J Neuroimmunol 232(1-2):119-130

22. Courret N, Darche S, Sonigo P et al (2006) CD11c- and CD11b-expressing mouse leukocytes transport single Toxoplasma gondii tachyzoites to the brain. Blood 107(1):309-316

23. Blader IJ, Saeij JP (2009) Communication between Toxoplasma gondii and its host: impact on parasite growth, development, immune evasion, and virulence. APMIS 117(5-6):458-476

24. Sauer A, Rochet E, Lahmar I et al (2013) The local immune response to intraocular Toxoplasma re-challenge: less pathology and better parasite control through Treg/ Th1/Th2 induction. Int J Parasitol 43(9):721-728

25. Guiton R, Vasseur V, Charron S et al (2010) Interleukin 17 receptor signaling is deleterious during Toxoplasma gondii infection in susceptible BL6 mice. J Infect Dis 202(3):427-435

26. O'Connor W Jr, Kamanaka M, Booth CJ et al (2009) A protective function for interleukin 17A in T cell-mediated intestinal inflammation. Nat Immunol 10(6):603-609

27. Hu M, Zheng Q, Jia X et al (2014) Neuroprotection effect of interleukin (IL)-17 secreted by reactive astrocytes is emerged from a high-level IL- 17-containing environment during acute neuroinflammation. Clin Exp Immunol 175(2):268-284

28. Hogan MJ (1958) Ocular toxoplasmosis: XIV Edward Jackson Memorial Lecture. Am J Ophthalmol 46:467-494

29. Holland GN. Ocular toxoplasmosis: a global reassessment: part II-disease manifestations and management. Am J Ophthalmol. 2004;137(1):1-17.

30. Howe DK, Sibley LD (1995) Toxoplasma gondii comprises three clonal lineages: correlation of parasite genotype with human disease. J Infect Dis 172(6):1561-1566

31. Grigg ME, Bonnefoy S, Hehl AB et al (2001) Success and virulence in Toxoplasma as the result of sexual recombination between two distinct ancestries. Science 294(5540):161-165

32. Su C, Evans D, Cole RH et al (2003) Recent expansion of Toxoplasma through enhanced oral transmission. Science 299(5605):414-416

33. Su C, Howe DK, Dubey JP et al (2002) Identification of quantitative trait loci controlling acute virulence in Toxoplasma gondii. Proc Natl Acad Sci USA 99(16):10753-10758 (Epub 2002 Jul 29)

34. Barragan A, Sibley LD (2002) Transepithelial migration of Toxoplasma gondii is linked to parasite motility and virulence. J Exp Med 195(12):1625-1633

35. Boothroyd JC, Grigg ME (2002) Population biology of Toxoplasma gondii and its relevance to human infection: Do different strains cause different disease? Curr Opin Microbiol 5(4):438-442

36. Fuentes I, Rubio JM, Ramirez C et al (2001) Genotypic characterization of Toxoplasma gondii strains associated with human toxoplasmosis in Spain: direct analysis from clinical samples. J Clin Microbiol 39(4):1566-1570

37. Grigg ME, Ganatra J, Boothroyd JC et al (2001) Unusual abundance of atypical strains associated with human ocular toxoplasmosis. J Infect Dis 184(5):633-639
38. Dubey JP, Graham DH, Blackston CR et al (2002) Biological and genetic characterisation of Toxoplasma gondii isolates from chickens (Gallus domesticus) from Sao Paulo, Brazil: unexpected findings. Int $\mathbf{J}$ Parasitol 32(1):99-105

39. Gilbert RE, Stanford MR, Jackson H et al (1995) Incidence of acute symptomatic Toxoplasma retinochoroiditis in south London according to country of birth. BMJ 310(6986): 1037-1040

40. Roizen N, Kasza K, Karrison T et al (2006) Impact of visual impairment on measures of cognitive function for children with congenital toxoplasmosis: implications for compensatory intervention strategies. Pediatrics 118(2): e379-e390

41. Bosch-Driessen LE, Berendschot TT, Ongkosuwito JV et al (2002) Ocular toxoplasmosis: clinical features and prognosis of 154 patients. Ophthalmology 109(5):869-878

42. Vasconcelos-Santos DV, Dodds EM, Orefice F (2011) Review for disease of the year: differential diagnosis of ocular toxoplasmosis. Ocul Immunol Inflamm 19(3):171-179

43. Fardeau C, Romand S, Rao NA et al (2002) Diagnosis of toxoplasmic retinochoroiditis with atypical clinical features. Am J Ophthalmol 134(2):196-203

44. Smith JR, Cunningham ET Jr (2002) Atypical presentations of ocular toxoplasmosis. Curr Opin Ophthalmol 13(6):387-392

45. Pichi F, Veronese C, Lembo A et al (2017) New appraisals of Kyrieleis plaques: a multimodal imaging study. Br J Ophthalmol 101(3):316-321. https://doi.org/10.1136/ bjophthalmol-2015-308246

46. Holland GN, O'Connor GR, Diaz RF et al (1988) Ocular toxoplasmosis in immunosuppressed nonhuman primates. Invest Ophthalmol Vis Sci 29(6):835-842

47. Roberts F, Mets MB, Ferguson DJ et al (2001) Histopathological features of ocular toxoplasmosis in the fetus and infant. Arch Ophthalmol 119(1):51-58

48. Dutton GN, McMenamin PG, Hay J, et al. The ultrastructural pathology of congenital murine toxoplasmic retinochoroiditis: part II-the morphology of the inflammatory changes. Exp Eye Res. 1986;43(4):545-60.

49. Maenz M, Schlüter D, Liesenfeld O (2014) Ocular toxoplasmosis past, present and new aspects of an old disease. Prog Retin Eye Res 39:77-106

50. de Souza EC, Casella AM (2009) Clinical and tomographic features of macular punctate outer retinal toxoplasmosis. Arch Ophthalmol 127(10):1390-1394

51. Doft BH, Gass DM (1985) Punctate outer retinal toxoplasmosis. Arch Ophthalmol 103(9):1332-1336

52. Yannuzzi NA, Gal-Or O, Motulsky E et al (2019) Multimodal imaging of punctate outer retinal toxoplasmosis. Ophthalmic Surg Lasers Imaging Retina 50(5):281-287. https://doi.org/10.3928/23258160-20190503-04

53. Fish RH, Hoskins JC, Kline LB (1993) Toxoplasmosis neuroretinitis. Ophthalmology 100(8):1177-1182

54. Miserocchi E, Modorati G, Rama P (2009) Atypical toxoplasmosis masquerading late occurrence of typical findings. Eur J Ophthalmol 19(6):1091-1093

55. Holland GN, Engstrom RE Jr, Glasgow BJ et al (1988) Ocular toxoplasmosis in patients with the acquired 
immunodeficiency syndrome. Am J Ophthalmol 106(6):653-667

56. Jensen E (1908) Retino-chorioiditis juxtapapillaris. Arch F Ophth 69:41

57. Rudich DS, Bhatnagar P (2012) Scleritis associated with toxoplasmic retinochoroiditis. Arch Ophthalmol 130(5):659-660

58. Schuman JS, Weinberg RS, Ferry AP et al (1988) Toxoplasmic scleritis. Ophthalmology 95(10):1399-1403

59. Dodds EM, Holland GN, Stanford MR (2008) Intraocular inflammation associated with ocular toxoplasmosis: relationships at initial examination. Am J Ophthalmol 146(6):856-65.e2

60. Melamed J, Eckert GU, Spadoni VS (2010) Ocular manifestations of congenital toxoplasmosis. Eye (Lond) 24(4):528-534

61. Adan A, Giralt J, Alvarez G et al (2009) Pars plana vitrectomy for vitreoretinal complications of ocular toxoplasmosis. Eur J Ophthalmol 19(6):1039-1043

62. Sousa DC, Andrade GC, Nascimento $\mathrm{H}$ et al. Macular hole associated with toxoplasmosis: a surgical case series. Retin Cases Brief Rep. 2018.

63. Kahloun R, Mbarek S, Khairallah-Ksiaa I et al (2013) Branch retinal artery occlusion associated with posterior uveitis. J Ophthalmic Inflamm Infect 3(1):16

64. Neri P, Mercanti L, Mariotti C et al (2010) Long-term control of choroidal neovascularization in quiescent congenital toxoplasma retinochoroiditis with photodynamic therapy: 4-year results. Int Ophthalmol 30(1):51-56

65. Benevento JD, Jager RD, Noble AG et al (2008) Toxoplasmosis-associated neovascular lesions treated successfully with ranibizumab and antiparasitic therapy. Arch Ophthalmol 126(8):1152-1156

66. Lavinsky D, Romano A, Muccioli C et al (2012) Imaging in ocular toxoplasmosis. Int Ophthalmol Clin 52(4):131-143

67. Pereira A, Orefice F (2001) Toxoplasmosis. In: Foster C, Vitale A (eds) Diagnosis and treatment of uveitis. W.B Sauders Company, Philadelphia, pp 385-410

68. Hassenstein A, Meyer CH (2009) Clinical use and research applications of Heidelberg retinal angiography and spectral-domain optical coherence tomography: a review. Clin Exp Ophthalmol 37(1):130-143

69. Weinberger AWA, Lappas A, Kirschkamp T et al (2006) Fundus near infrared fluorescence correlates with fundus near infrared reflectance. Invest Ophthalmol Vis Sci 47(7):3098-3108

70. Schmitz-Valckenberg S, Holz FG, Bird AC et al (2008) Fundus autofluorescence imaging: review and perspectives. Retina 28(3):385-409

71. Onal S, Tugal-Tutkun I, Neri P, P Herbort C. Optical coherence tomography imaging in uveitis. Int Ophthalmol. 2014;34(2):401-435. https://doi.org/10.1007/s10792-0139822-7.

72. de Oliveira Dias JR, Campelo C, Novais EA, et al. New findings useful for clinical practice using swept-source optical coherence tomography angiography in the followup of active ocular toxoplasmosis. Int J Retina Vitreous. 2020;6:30. https://doi.org/10.1186/s40942-020-00231-2.

73. Spaide RF (2015) Volume rendering of optical coherence tomography angiography reveals extensive retinal vascular contributions to neovascularization in ocular toxoplasmosis. Retina 35(11):2421-2422. https://doi.org/ 10.1097/IAE.0000000000000721

74. Park JH, Lee SY, Lee EK. Morphological characteristics of ocular toxoplasmosis and its regression pattern on swept-source optical coherence tomography angiography: a case report. BMC Ophthalmol. 2019;19(1):199. https:// doi.org/10.1186/s12886-019-1209-8.

75. Türkcü FM, Şahin A, Yüksel H, Şahin M, Karaalp Ü (2017) OCTA imaging of choroidal neovascular membrane secondary to toxoplasma retinochoroiditis. Ophthalmic Surg Lasers Imaging Retina 48(6):509-511. https://doi.org/10.3928/23258160-20170601-11

76. Saadatnia G, Golkar M (2012) A review on human toxoplasmosis. Scand J Infect Dis 44(11):805-811

77. Montoya J (2002) Laboratory diagnosis of Toxoplasma gondii infection and toxoplasmosis. J Infect Dis 185(Suppl 1):S73-82

78. Abdul-Ghani R (2011) Polymerase chain reaction in the diagnosis of congenital toxoplasmosis: more than two decades of development and evaluation. Parasitol Res 108(3):505-512

79. Remington JS, Thulliez P, Montoya JG (2004) Recent developments for diagnosis of toxoplasmosis. J Clin Microbiol 42(3):941-945

80. Bastien P. Molecular diagnosis of toxoplasmosis: transactions of the royal society of tropical medicine and hygiene. Trans R Soc Trop Med Hyg. 2002;96 Suppl 1:S205-15.

81. Dabil H, Boley ML, Schmitz TM, Van Gelder RN (2001) Validation of a diagnostic multiplex polymerase chain reaction assay for infectious posterior uveitis. Arch Ophthalmol 119(9):1315-1322

82. Sterkers Y, Varlet-Marie E, Cassaing S et al (2010) Multicentric comparative analytical performance study for molecular detection of low amounts of Toxoplasma gondii from simulated specimens. J Clin Microbiol 48(9):3216-3222

83. Reischl U, Bretagne S, Krüger D et al (2003) Comparison of two DNA targets for the diagnosis of Toxoplasmosis by real-time PCR using fluorescence resonance energy transfer hybridization probes. BMC Infect Dis 3(1):7

84. Harper T, Miller D, Schiffman J et al (2009) Polymerase chain reaction analysis of aqueous and vitreous specimens in the diagnosis of posterior segment infectious uveitis. Am J Opthalmol 147(1):140-147

85. Farhadi A, Haniloo A, Fazaeli A et al (2017) PCR-based diagnosis of Toxoplasma parasite in ocular infections having clinical indications of toxoplasmosis. Iran J Parasitol 12(1):56-62

86. Gomez C, Sahoo M, Kahn GY et al (2019) Dual-target, real-time PCR for the diagnosis of intraocular Toxoplasma gondii infections. Br J Opthalmol 103:569-572

87. Bourdin C, Busse A, Kouamou E et al (2014) PCR-based detection of Toxoplasma gondii in blood and ocular samples for diagnosis of ocular toxoplasmosis. J Clin Microbiol 52(11):3987-3991

88. Garweg G, Groot-Mijnes J, Montoya J (2011) Diagnostic approach to ocular toxoplasmosis. Ocul Immunol Inflamm 19(4):255-261 
89. Robert-Gangneux F, Belaz S (2016) Molecular diagnosis of toxoplasmosis in immunocompromised patients. Curr Opin Infect Dis 29(4):330-339. https://doi.org/10.1097/ QCO.0000000000000275

90. Fekkar A, Bodaghi B, Touafek F, Le Hoang P, Mazier D, Paris L (2008) Comparison of immunoblotting, calculation of the Goldmann-Witmer coefficient, and real-time PCR using aqueous humor samples for diagnosis of ocular toxoplasmosis. J Clin Microbiol 46(6):1965-1967. https:// doi.org/10.1128/JCM.01900-07

91. Liu Q, Wang Z-D, Huang S-Y et al (2015) Diagnosis of toxoplasmosis and typing of Toxoplasma gondii. Parasit Vectors 8:292

92. Wassef R, Abdel-Malek R (2019) Validity of a new immunochromatographic test in detection of Toxoplasma gondii in cancer patients. J Parasit Dis 43(1):83-86

93. Bonfioli AA, Orefice F (2005) Toxoplasmosis. Semin Ophthalmol 20(3):129-141

94. Gras L, Gilbert RE, Wallon M et al (2004) Duration of the IgM response in women acquiring Toxoplasma gondii during pregnancy: implications for clinical practice and cross-sectional incidence studies. Epidemiol Infect 132(3):541-548

95. Olariu TR, Press C, Talucod J et al (2019) Congenital toxoplasmosis in the United States: clinical and serologic findings in infants born to mothers treated during pregnancy. Parasite 26:13

96. Findal G, Pedersen-Stray B, Holter E, et al. Persistent low Toxoplasma IgG avidity is common in pregnancy: experience from antenatal testing in Norway. PLoS One. 2015;10(12):e0145519.

97. Villena ID, Aubert D, Brodard V, et al. Detection of specific immunoglobulin E during maternal, fetal, and congenital toxoplasmosis. J Clin Microbiol 1999;37(11):3487-90.

98. Roh M, Yasa C, Cho H et al (2016) The role of serological titres in the diagnosis of ocular toxoplasmosis. Acta Ophthalmol 94(5):521-522

99. Papadia M, Aldigeri F, Herbort C (2011) The role of serology in active ocular toxoplasmosis. Int Ophthalmol 31(6):461-465

100. Silveira C, Vallochi AL, Rodrigues da Silva U, et al. Toxoplasma gondii in the peripheral blood of patients with acute and chronic toxoplasmosis. $\mathrm{Br} \mathrm{J}$ Ophthalmol. 2011;95(3):396-400. https://doi.org/10.1136/bjo.2008. 148205.

101. Kijlstra A, Luyendijk L, Baarsma GS et al (1989) Aqueous humor analysis as a diagnostic tool in toxoplasma uveitis. Int Ophthalmol 13(6):383-386. https://doi.org/10.1007/ BF02306485

102. Ozgonul C, Besirli CG (2017) Recent developments in the diagnosis and treatment of ocular toxoplasmosis. Ophthalmic Res 57(1):1-12. https://doi.org/10.1159/ 000449169

103. von Goldman H, Witmer R (1954) Antikoperimkammerwasser. Ophthalmologica 127:323-330

104. Villard O, Cimon B, L'Ollivier C et al (2016) Serological diagnosis of Toxoplasma gondii infection: recommendations from the french national reference center for toxoplasmosis. Diagn Microbiol Infect Dis 84(1):22-33
105. Rothova A, de Boer JH, Ten Dam-van Loon NH et al (2008) Usefulness of aqueous humor analysis for the diagnosis of posterior uveitis. Ophthalmology 115(2):306-311. https://doi.org/10.1016/j.ophtha.2007. 05.014

106. Fawzy M, Mahmoud LA, El Gindy AE et al (1999) Value of estimating intraocular antibody production in diagnosis of typical and atypical lesions of ocular toxoplasmosis. J Egypt Soc Parasitol 29(3):735-743

107. Mathis T, Beccat S, Sève P, Peyron F, Wallon M, Kodjikian L (2018) Comparison of immunoblotting (IgA and $\mathrm{IgG}$ ) and the Goldmann-Witmer coefficient for diagnosis of ocular toxoplasmosis in immunocompetent patients. $\mathrm{Br}$ J Ophthalmol 102(10):1454-1458. https://doi.org/10. 1136/bjophthalmol-2017-311528

108. Robert-Gangneux F, Binisti P, Antonetti D, Brezin A, Yera H, Dupouy-Camet J (2004) Usefulness of immunoblotting and Goldmann-Witmer coefficient for biological diagnosis of toxoplasmic retinochoroiditis. Eur J Clin Microbiol Infect Dis 23(1):34-38. https://doi.org/10.1007/s10096003-1048-6

109. Garweg JG, Garweg SD, Flueckiger F et al (2004) Aqueous humor and serum immunoblotting for immunoglobulin types $\mathrm{G}, \mathrm{A}, \mathrm{M}$, and $\mathrm{E}$ in cases of human ocular toxoplasmosis. J Clin Microbiol 42(10):4593-4598

110. Previato M, Frederico FB, Murata FH et al (2015) A Brazilian report using serological and molecular diagnosis to monitoring acute ocular toxoplasmosis. BMC Res Notes $8: 746$

111. Chapey E, Wallon M, Debize G, Rabilloud M, Peyron F (2010) Diagnosis of congenital toxoplasmosis by using a whole-blood gamma interferon release assay. J Clin Microbiol 48(1):41-45. https://doi.org/10.1128/JCM. 01903-09

112. de Araújo TE, Dos Santos LI, Gomes AO, et al. Putative biomarkers for early diagnosis and prognosis of congenital ocular toxoplasmosis. Sci Rep. 2020;10(1):16757. https:// doi.org/10.1038/s41598-020-73265-z.

113. Meira CS, Pereira-Chioccola VL, Vidal JE, et al. Cerebral and ocular toxoplasmosis related with IFN- $\gamma, \mathrm{TNF}-\alpha$, and IL-10 levels. Front Microbiol. 2014;5:492. https://doi.org/ 10.3389/fmicb.2014.00492.

114. Gross U. Prävalenz und Public-Health-Aspekte der Toxoplasmose. Bundesgesundheitsblatt-Gesundheitsforschung-Gesundheitsschutz. 2004;1;47(7):692-7.

115. Bidgoli S, Koch P, Caspers L (2011) Toxoplasmic chorioretinitis: positive PCR on vitreous with negative serology for Toxoplasma gondii. J Françaisd'ophtalmologie 34(6):384-e1

116. Vasconcelos-Santos DV (2012) Ocular manifestations of systemic disease: toxoplasmosis. Curr Opin Ophthalmol 23(6):543-50

117. Wilder HC (1952) Toxoplasma chorioretinitis in adults. AMA Arch Ophthalmol 48(2):127-36

118. Rothova A, Meenken C, Buitenhuis HJ et al (1993) Therapy for ocular toxoplasmosis. Am J Ophthalmol 115(4):517-23

119. Stanford MR, Gilbert RE (2009) Treating ocular toxoplasmosis: current evidence. Mem Inst Oswaldo Cruz 104(2):312-5 
120. Reichard U, Gross U (2007) Toxoplasma animal models and therapeutics. In: Weiss LM, Kim K (eds) Toxoplasma gondii: the model apicomplexan-perspectives and methods. Amsterdam, Elsevier Academic Press, pp 153-184

121. Orefice F, Bonfioli AA (2000) Toxoplasmosis. In: Orefice F (ed) Uveitis-Clinica e Cirurgica, 1st edn. CulturaMedica, Rio de Janeiro, pp 680-784

122. Holland GN, Lewis KG (2002) An update on current practices in the management of ocular toxoplasmosis. Am J Ophthalmol 134(1):102-14

123. Soheilian M, Sadoughi MM, Ghajarnia M et al (2005) Prospective randomized trial of trimethoprim/ sulfamethoxazole versus pyrimethamine and sulfadiazine in the treatment of ocular toxoplasmosis. Ophthalmology 112(11):1876-82

124. Silveira C, Belfort R Jr, Muccioli C et al (2002) The effect of long-term intermittent trimethoprim/ sulfamethoxazole treatment on recurrences of toxoplasmic retinochoroiditis. Am J Ophthalmol 134(1):41-6

125. Lam S, Tessler HH (1993) Quadruple therapy for ocular toxoplasmosis. Can J Ophthalmol 28(2):58-61

126. Martinez CE, Zhang D, Conway MD, et al. Successful management of ocular toxoplasmosis during pregnancy using combined intraocular clindamycin and dexamethasone with systemic sulfadiazine. Int Ophthalmol. 1998-1999;22(2):85-8.

127. Kishore K, Conway MD, Peyman GA (2001) Intravitreal clindamycin and dexamethasone for toxoplasmic retinochoroiditis. Ophthalmic Surg Lasers 32(3):183-92

128. Lasave AF, Diaz-Llopis M, Muccioli C et al (2010) Intravitreal clindamycin and dexamethasone for zone 1 toxoplasmic retinochoroiditis at twenty-four months. Ophthalmology 117(9):1831-8

129. Soheilian M, Ramezani A, Azimzadeh A, et al. Randomized trial of intravitreal clindamycin and dexamethasone versus pyrimethamine, sulfadiazine, and prednisolone in treatment of ocular toxoplasmosis Ophthalmology. 2011;118(1):134-41.

130. Butler NJ, Furtado JM, Winthrop KL et al (2013) Ocular toxoplasmosis II: clinical features, pathology and management. Clin Exp Ophthalmol 41(1):95-108

131. Cunningham ET Jr, Hubbard LD, Danis RP et al (2011) Proportionate topographic areas of retinal zones 1,2, and 3 for use in describing infectious retinitis. Arch Ophthalmol 129(11):1507-8

132. Bosch-Driessen LH, Verbraak FD, Suttorp-Schulten MS et al (2002) A prospective, randomized trial of pyrimethamine and azithromycin vs pyrimethamine and sulfadiazine for the treatment of ocular toxoplasmosis. Am J Ophthalmol 134(1):34-40

133. Bosch-Driessen EH, Rothova A (1998) Sense and nonsense of corticosteroid administration in the treatment of ocular toxoplasmosis. Br J Ophthalmol 82(8):858-60
134. Nozik RA (1977) Results of treatment of ocular toxoplasmosis with injectable corticosteroids. Trans Sect Ophthalmol Am Acad Ophthalmol Otolaryngol 83(5):811-8

135. Aggio FB, Muccioli C, Belfort R Jr (2006) Intravitreal triamcinolone acetonide as an adjunct in the treatment of severe ocular toxoplasmosis. Eye (Lond) 20:1080-2

136. Backhouse O, Bhan KJ, Bishop F (2008) Intravitreal triamcinolone acetonide as an adjunct in the treatment of severe ocular toxoplasmosis. Eye (Lond) 22:1201-2

137. Zhang Y, Lin X, Lu F (2018) Current treatment of ocular toxoplasmosis in immunocompetent patients: a network meta-analysis. Acta Trop 185:52-62

138. Kump LI, Androudi SN, Foster CS (2005) Ocular toxoplasmosis in pregnancy. Clin Exp Ophthalmol 33(5):455-60

139. Garweg JG, Scherrer J, Wallon M, Kodjikian L, Peyron F (2005) Reactivation of ocular toxoplasmosis during pregnancy. BJOG 112(2):241-242. https://doi.org/10.1111/j. 1471-0528.2004.00302.x

140. Montoya JG, Remington JS (2008) Management of Toxoplasma gondii infection during pregnancy. Clin Infect Dis 47(4):554-566. https://doi.org/10.1086/590149

141. Holland, GN.; O'Connor, GR.; Belfort, R., Junior; Remington, JS. Toxoplasmosis. In: Pepose, JS.; Holland, GN.; Wilhelmus, KR., editors. Ocular infection and immunity. St. Louis: Mosby; 1996. p. 1183-223.

142. Holland GN, Crespi CM, ten Dam-van LN et al (2008) Analysis of recurrence patterns associated with toxoplasmic retinochoroiditis. Am J Ophthalmol 145(6):1007-1013

143. Engstrom RE Jr, Holland GN, Nussenblatt RB, Jabs DA (1991) Current practices in the management of ocular toxoplasmosis. Am J Ophthalmol 111(5):601-10

144. Asproudis I, Koumpoulis I, Kalogeropoulos C et al (2013) Case report of a neonate with ocular toxoplasmosis due to congenital infection: estimation of the percentage of ocular toxoplasmosis in Greece caused by congenital or acquired infection. Clin Ophthalmol 7:2249-52

145. Stillwaggon E, Carrier CS, Sautter M, et al. Maternal serologic screening to prevent congenital toxoplasmosis: a decision-analytic economic model. PLoS Negl Trop Dis. 2011;5(9):e1333.

146. Gilbert RE, Freeman K, Lago EG, et al. Ocular sequelae of congenital toxoplasmosis in Brazil compared with Europe. PLoS Negl Trop Dis. 2008;2(8):e277.

147. da Mata AP, Orefice F (2002) Toxoplasmosis. In: Foster CS, Vitale AT (eds) Diagnosis and treatment of uveitis. WB Saunders, Philadelphia, pp 385-410

Publisher's Note Springer Nature remains neutral with regard to jurisdictional claims in published maps and institutional affiliations. 